\title{
Laparoendoscopic Single-site and Natural Orifice Transluminal Endoscopic Surgery in Urology: A Critical Analysis of the Literature
}

\author{
Riccardo Autorino ${ }^{a, b, *}$, Jeffrey A. Cadeddu ${ }^{c}$, Mihir M. Desai $^{d}$, Matthew Gettman $^{e}$, \\ Inderbir S. Gill ${ }^{d}$, Louis R. Kavoussi ${ }^{f}$, Estevão Lima $^{g}$, Francesco Montorsi ${ }^{h}$, Lee Richstone ${ }^{f}$, \\ Jens U. Stolzenburg ${ }^{i}$, Jihad H. Kaouk ${ }^{a}$ \\ ${ }^{a}$ Glickman Urological and Kidney Institute, Cleveland Clinic, Cleveland, Ohio, USA \\ ${ }^{\mathrm{b}}$ Urology Clinic, Second University of Naples, Naples, Italy \\ ${ }^{\mathrm{c}}$ Department of Urology, University of Texas Southwestern Medical Center, Dallas, Texas, USA \\ ${ }^{\mathrm{d}}$ Institute of Urology, Keck School of Medicine, University of Southern California, Los Angeles, California, USA \\ ${ }^{\mathrm{e}}$ Department of Urology, Mayo Clinic, Rochester, Minnesota, USA \\ ${ }^{\mathrm{f}}$ Smith Institute for Urology, Long Island Jewish Health System, New Hyde Park, New York, USA \\ ${ }^{\mathrm{g}}$ Life and Health Sciences Research Institute, School of Health Sciences, University of Minho, Braga, Portugal \\ ${ }^{\mathrm{h}}$ Department of Urology, Hospital San Raffaele, University Vita-Salute, Milan, Italy \\ ${ }^{\mathrm{i}}$ Department of Urology, University of Leipzig, Leipzig, Germany
}

\section{Article info}

\section{Article history:}

Accepted August 17, 2010

Published online ahead of

print on August 27, 2010

\section{Keywords:}

Laparoendoscopic single-site

surgery

Laparoscopy

LESS

Natural orifice transluminal

endoscopic surgery

NOTES

Robotics

Urology

\section{EU * ACME}

www.eu-acme.org/

europeanurology

Please visit www.eu-acme.org/ europeanurology to read and answer questions on-line. The EU-ACME credits will then be attributed automatically.

\begin{abstract}
Context: Natural orifice transluminal endoscopic surgery (NOTES) and laparoendoscopic single-site surgery (LESS) have been developed to benefit patients by enabling surgeons to perform scarless surgery.

Objective: To summarize and critically analyze the available evidence on the current status and future perspectives of LESS and NOTES in urology.

Evidence acquisition: A comprehensive electronic literature search was conducted in June 2010 using the Medline database to identify all publications relating to NOTES and LESS in urology.

Evidence synthesis: In urology, NOTES has been completed experimentally via transgastric, transvaginal, transcolonic, and transvesical routes. Initial clinical experience has shown that NOTES urologic surgery using currently available instruments is indeed possible. Nevertheless, because of the immaturity of the instrumentation, early cases have demanded high technical virtuosity. LESS can safely and effectively be performed in a variety of urologic settings. As clinical experience increases, expanding indications are expected to be documented and the efficacy of the procedure to improve. So far, the quality of evidence of all available studies remains low, mostly being small case series or casecontrol studies from selected centers. Thus, the only objective benefit of LESS remains the improved cosmetic outcome. Prospective, randomized studies are largely awaited to determine which LESS procedures will be established and which are unlikely to stand the test of time. Technology advances hold promise to minimize the challenging technical nature of scarless surgery. In this respect, robotics is likely to drive a major paradigm shift in the development of LESS and NOTES.

Conclusions: NOTES is still an investigational approach in urology. LESS has proven to be immediately applicable in the clinical field, being safe and feasible in the hands of experienced laparoscopic surgeons. Development of instrumentation and application of robotic technology are expected to define the actual role of these techniques in minimally invasive urologic surgery.

C 2010 European Association of Urology. Published by Elsevier B.V. All rights reserved.
\end{abstract}

* Corresponding author. Glickman Urological and Kidney Institute, Cleveland Clinic, 9500 Euclid Ave., 44195, Cleveland, Ohio, USA. Tel. +1 216444 1047; Fax: +1 2164452267. E-mail address: ricautor@tin.it, autorir@ccf.org (R. Autorino). 


\section{Introduction}

Natural orifice transluminal endoscopic surgery (NOTES) and laparoendoscopic single-site surgery (LESS) have been developed in an attempt to further reduce the morbidity and scarring associated with surgical intervention. Conceptually, these techniques share a common underlying "hypothesis" that has driven their development-namely, that a reduction in the number of transcutaneous points of access may benefit patients in terms of port-related complications, recovery time, pain, and cosmesis by potentially performing scarless surgery [1].

NOTES involves diagnostic or therapeutic interventions performed via existing orifices of the human body (mouth, anus, urethra, vagina). Although a "pure" NOTES procedure is performed without transabdominal access, the use of accessory transabdominal ports has been regarded as part of the evolution of NOTES and defined as hybrid NOTES [2].

In urology, the concept of NOTES was initiated with the use of natural orifices to extract surgical specimens. In 1993, vaginal extraction of an intact kidney following laparoscopic radical nephrectomy (LRN) was first described by Breda et al. [3]. In 2002, Gill et al reported an LRN series employing this natural orifice specimen extraction [4]. Subsequently, DeGer et al reported on laparoscopic cystectomy performed completely intracorporeally, with transvaginal or rectal specimen extraction [5].

The first experimental NOTES procedure in urology was reported by Gettman et al, who described a successful transvaginal nephrectomy in pigs [6]. This work predated the first recognized NOTES report on transgastric peritoneoscopy by Kalloo et al in the gastroenterology literature [7]. Later, another NOTES portal-the bladder-was employed for the first time by Lima et al in a porcine model [8]. The transition to clinical NOTES in urology has been slow, and the first "pure" NOTES simple nephrectomy in a human has been only recently reported by Kaouk et al. [9].

Technical challenges associated with NOTES have led to an increasing interest in single-incision or single-port laparoscopy. Several terms and acronyms have been used to refer to this technique until a consensus statement agreed to use the term LESS [2]. Regarded as the latest evolution in laparoscopic surgery, LESS claims to provide benefits similar to NOTES, mainly with enhanced cosmesis without the added risks associated with viscerotomy [2].

Hirano et al were the first to report urologic singleincision surgery in 2005 [10]. They used a resectoscope tube and standard laparoscopic instruments to show the feasibility of retroperitoneoscopic adrenalectomy. In 2007, two groups independently reported the first LESS transumbilical nephrectomy [11,12]. Since then, clinical series have been reported, with almost the entire spectrum of urologic procedures described [13]. The aim of this review is to summarize and critically analyze the available evidence on the current status and future perspectives of LESS and NOTES in urologic surgery.

\section{Evidence acquisition}

\subsection{Literature search}

A comprehensive electronic literature search was conducted in June 2010 using the Medline database-through either PubMed or Ovid as a search engine-to identify all publications relating to NOTES and LESS in urology. Both experimental (animal and cadaver) and clinical research studies were considered. English language articles were included for review, and non-English articles were included if they provided additional, relevant information.

The search was conducted using a free-text protocol that included the following terms: natural orifice transluminal endoscopic surgery (NOTES); laparoendoscopic single-site surgery (LESS); robot-assisted NOTES (R-NOTES); single-port access (SPA) surgery; robot-assisted single-port surgery; single-incision laparoscopic surgery (SILS); single-port laparoscopy (SPL); single-incision laparoscopy (SIL); scarless urologic surgery; one-port umbilical surgery (OPUS); embryonic NOTES (E-NOTES); umbilical NOTES (U-NOTES); keyhole (umbilical) surgery; single-trocar laparoscopic surgery; and single-access-site laparoscopic surgery. These terms were arranged by variable combinations of the Boolean operators AND and OR. Moreover, pertinent information on purpose-built instrumentation and technology for NOTES and LESS was obtained by accessing company Web sites and by considering experience from the panel of experts.

\subsection{Inclusion criteria}

Attention was given only to published materials pertaining to the field urology as based on the journal, authorship, and/ or content. Editorials and letters to the editor were not included. Review articles and case reports were considered if they were relevant. Studies published as abstracts only and reports from meetings were not included. Other significant studies cited in the reference lists of the selected papers were evaluated. Publications reporting on the same cohort group from the same institution were limited to the most recent publication. Overall, the list of source items was discussed by the panel of authors in order to select relevant articles.

\subsection{Quality of evidence}

Studies were rated for the level of evidence provided according to criteria by the Centre for Evidence Based Medicine in Oxford, United Kingdom.

\section{Evidence synthesis}

The concept of scarless surgical procedures has evoked great interest among urologists, as documented by the increasing number of scientific publications on this topic in the past $3 \mathrm{yr}$ (Fig. 1). 


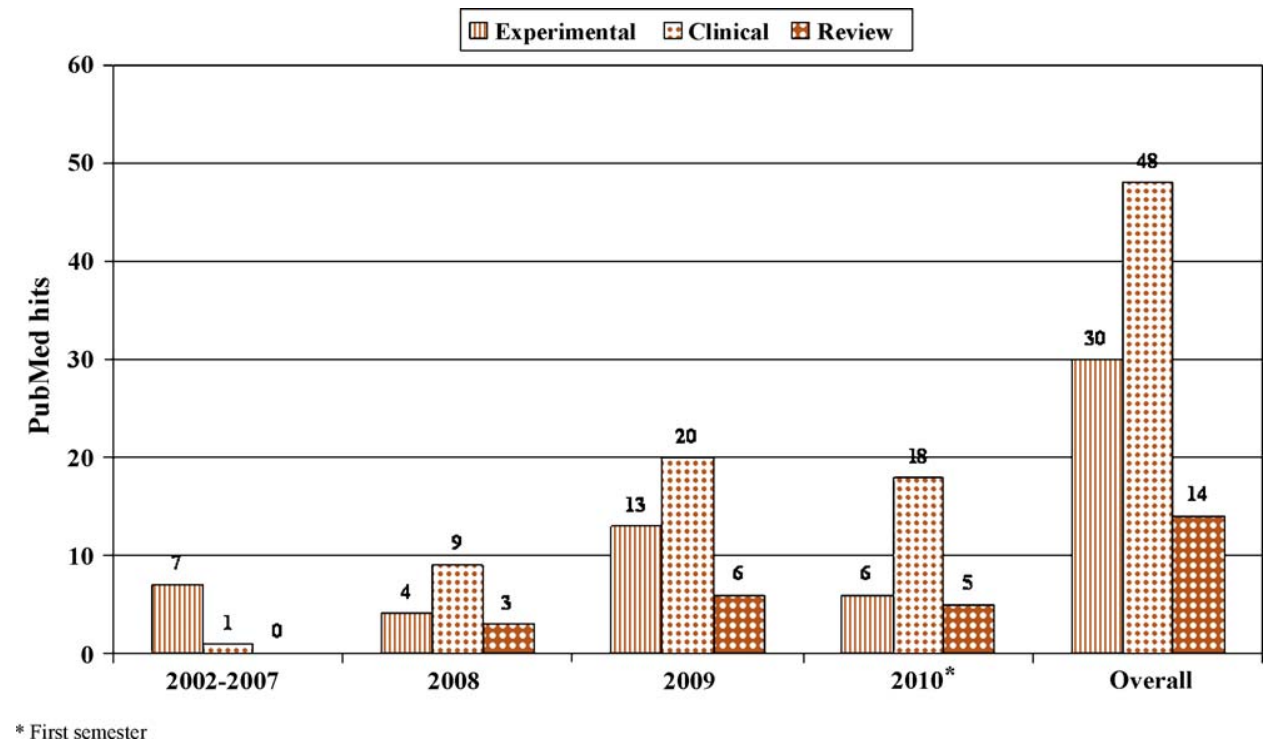

Fig. 1 - Publications (PubMed hits) on natural orifice transluminal endoscopic surgery and laparoendoscopic single-site surgery in urology literature.

3.1. Experimental natural orifice transluminal endoscopic surgery and laparoendoscopic single-site surgery

\subsubsection{Natural orifice transluminal endoscopic surgery: access and} urologic procedures

The steps of transvisceral surgery are almost universal [14]: (1) access through a natural orifice with a multichannel scope; (2) incision through the visceral wall using a needleknife; (3) placement of a wire into the abdominal cavity using a modified Seldinger technique; (4) use of a dilating balloon to obtain a suitable access tract; (5) placement of a catheter, guide tube, or overtube over the guidewire and
$\mathrm{CO}_{2}$ insufflation; (6) advancement of the scope; (7) completion of the diagnostic/operative procedure; and (8) viscerotomy closure.

Thus far, NOTES has been successfully completed experimentally via transgastric [15], transvaginal [16], transcolonic [17], and transvesical [18] routes (Table 1). Kalloo et al demonstrated the feasibility of transgastric access to the peritoneal cavity in a porcine model [5]. However, the possibility of carrying out abdominal procedures through an isolated transgastric route faced several limitations. In attempting to overcome them, the combination of transgastric access with a transabdominal port

Table 1 - Comparing natural orifice transluminal endoscopic surgery access routes: experimental development in a porcine model [9,14-18]

\begin{tabular}{|c|c|c|c|c|}
\hline & Vagina & Stomach & Colon & Bladder \\
\hline First description (yr) & Gettman (2002) & Kalloo (2004) & Pai (2006) & Lima (2006) \\
\hline Pros & $\begin{array}{l}\text { - En face visualization of } \\
\text { upper urinary tract } \\
\text { - Ease of closure } \\
\text { - Use of both flexible and } \\
\text { rigid instruments } \\
\text { - Highly compliant } \\
\text { (specimen retrieval) }\end{array}$ & $\begin{array}{l}\text { - Available in both } \\
\text { genders }\end{array}$ & $\begin{array}{l}\text { - En face visualization of } \\
\text { upper urinary tract } \\
\text { - Available in both genders } \\
\text { - Use of both flexible and } \\
\text { rigid instruments } \\
\text { - Highly compliant } \\
\text { (specimen retrieval) }\end{array}$ & $\begin{array}{l}\text { - En face visualization of } \\
\text { upper urinary tract } \\
\text { - Available in both genders } \\
\text { - Use of both flexible and } \\
\text { rigid instruments } \\
\text { - Sterility }\end{array}$ \\
\hline Cons & $\begin{array}{l}\text { - Only available in female } \\
\text { - Lack of sterility } \\
\text { (risk of infection) }\end{array}$ & $\begin{array}{l}\text { - Lack of sterility } \\
\text { (risk of infection) } \\
\text { - Lack of reliable } \\
\text { closing system } \\
\text { - Exclusive use of } \\
\text { flexible instruments } \\
\text { - Difficult spatial } \\
\text { orientation } \\
\text {-Specimen retrieval } \\
\text { (limited) }\end{array}$ & $\begin{array}{l}\text { - Highly contaminated } \\
\text { (risk of infection) } \\
\text { - Lack of reliable } \\
\text { closing system }\end{array}$ & $\begin{array}{l}\text { - Limited luminal diameter } \\
\text { (specimen retrieval } \\
\text { not allowed) }\end{array}$ \\
\hline $\begin{array}{l}\text { Experimental } \\
\text { application in urology }\end{array}$ & Yes & Yes & Yes & Yes \\
\hline $\begin{array}{l}\text { Clinical application } \\
\text { in urology }\end{array}$ & Yes $[9,72-75]$ & No & No & Yes [18] \\
\hline
\end{tabular}


(hybrid approach) or with a lower-abdominal natural orifice point of access (pure NOTES combined approach) has been proposed [19].

One of the most important factors when performing NOTES is the secure closure of the portal. As mentioned, the vagina is suitable for specimen extraction [3,4], and its closure is safely performed using standard surgical techniques, as demonstrated in gynecologic literature. Performing transvaginal surgery allows for in-line direct visualization of upper-tract urologic organs, allowing the use of rigid instruments and minimizing difficulties with spatial orientation.

For upper-abdominal exploration and interventions, en face visualization of the retroperitoneal space and urogenital system through a transcolonic approach is comparable to the transvaginal route, with the additional benefit of not being limited by the gender of the patient. Furthermore, it allows for insertion of larger-diameter instruments and removal of large specimens. Although the transcolonic approach to NOTES has been shown to be technically feasible in multiple animal studies [19], concern for security of the closure and the related risk of infection remain the most worrisome obstacle to the transfer of transcolonic NOTES to human trials.

Lima et al were the first to assess the feasibility of a transvesical port by performing a peritoneoscopy with a semi-rigid ureteroscope [8]. In 2007, Gettman and Blute applied transvesical NOTES in the clinical setting, performing a peritoneoscopy prior to robotic radical prostatectomy (RP) [18]. The transvesical access site is placed at the most anterior position in the bladder dome to reduce the risk of visceral injury. Advantages of this access site are that it is inherently sterile and available in both genders [18]. Moreover, although small bladder perforations could be safely managed with bladder drainage, Lima et al described an endoscopic closure of vesicostomy following a transvesical NOTES approach [20].

A single NOTES access raises limitations while performing complex urologic procedures related to exposure, organ retraction, grasping, and limited triangulation. The concept of effectively combining transgastric and transvesical access was demonstrated by Lima et al, who performed a pure NOTES nephrectomy in a non-survival porcine model [21]. In their initial transvaginal nephrectomy, Gettman et al used a single 5-mm transabdominal trocar to facilitate visualization in five of six cases [6]. Two survival animals were monitored for $1 \mathrm{wk}$ after the first procedure. Both had normal bowel function and urination, and vaginoscopy demonstrated healed posterior colpotomy incisions. The authors concluded that although feasible in the pig, hybrid NOTES nephrectomy was far from being ready for human application.

Since 2007, other groups have started to revisit the concept of NOTES applications in urology (Table 2).

Table 2 - Experimental application of natural orifice transluminal endoscopic surgery: milestones in urologic literature

\begin{tabular}{|c|c|c|c|c|c|}
\hline Yr & Author & Model & Access & $\begin{array}{l}\text { Which procedure is } \\
\text { demonstrated to be feasible }\end{array}$ & Which drawbacks it points out \\
\hline 2002 & Gettman [6] & $\begin{array}{l}\text { Porcine, acute } \\
\text { and chronic }\end{array}$ & Transvaginal & $\begin{array}{l}\text { NOTES and hybrid NOTES } \\
\text { transvaginal nephrectomy }\end{array}$ & $\begin{array}{l}\text { The procedure is technically cumbersome } \\
\text { and difficult to complete with available technology. }\end{array}$ \\
\hline \multirow[t]{2}{*}{2007} & Clayman [22] & Porcine, acute & Transvaginal & $\begin{array}{l}\text { Hybrid NOTES transvaginal } \\
\text { nephrectomy using a } \\
\text { purpose-built NOTES } \\
\text { multilumen platform (TransPort) }\end{array}$ & $\begin{array}{l}\text { Adequate retraction, dissection, and hilum } \\
\text { management are challenging using this platform. }\end{array}$ \\
\hline & Lima [21] & Porcine, acute & $\begin{array}{l}\text { Transgastric } \\
\text { Transvesical }\end{array}$ & $\begin{array}{l}\text { NOTES nephrectomy using a } \\
\text { combined approach }\end{array}$ & $\begin{array}{l}\text { Current ureteroscopes are far from the ideal } \\
\text { design to be used in NOTES. } \\
\text { Safe closure of the gastrostomy and specimen } \\
\text { removal remains to be determined. }\end{array}$ \\
\hline 2008 & Crouzet [24] & Porcine, acute & $\begin{array}{l}\text { Transgastric } \\
\text { Transvaginal }\end{array}$ & NOTES renal cryoablation & $\begin{array}{l}\text { Suitable instrumentation to use through the } \\
\text { gastroscope and a specific NOTES cryoprobe } \\
\text { are lacking. Retraction with gastroscope is } \\
\text { limited. }\end{array}$ \\
\hline \multirow[t]{4}{*}{2009} & Haber [23] & Porcine, acute & Transvaginal & NOTES transvaginal nephrectomy & $\begin{array}{l}\text { There is need for a specifically designed } \\
\text { vaginal port, suitable instrumentation to use } \\
\text { through the gastroscope, and articulated } \\
\text { Endocatch bag to facilitate single-handed } \\
\text { entrapment of specimen. }\end{array}$ \\
\hline & Boylu [25] & Porcine, acute & Transgastric & $\begin{array}{l}\text { NOTES transgastric PN using a } \\
\text { thulium laser }\end{array}$ & $\begin{array}{l}\text { Excessive smoke is produced by tissue vaporization. } \\
\text { No entrapment sac that can be introduced through } \\
\text { the gastroscope is available. }\end{array}$ \\
\hline & Humphreys [26] & Cadaver & Transurethral & NOTES RP & $\begin{array}{l}\text { Procedure has been performed in the absence of } \\
\text { bleeding or physiologic consequences. Technical } \\
\text { limitations are present for vesicourethral } \\
\text { anastomosis. Lack of intact specimen for } \\
\text { pathology is an issue. Node dissection is } \\
\text { not possible. }\end{array}$ \\
\hline & Sawyer [27] & $\begin{array}{l}\text { Porcine, acute } \\
\text { and chronic }\end{array}$ & $\begin{array}{l}\text { Transgastric } \\
\text { Transurethral }\end{array}$ & $\begin{array}{l}\text { NOTES partial cystectomy } \\
\text { using both approaches }\end{array}$ & $\begin{array}{l}\text { Lack of triangulation, difficult orientation, and } \\
\text { deficiencies in the equipment have been found. }\end{array}$ \\
\hline
\end{tabular}


Clayman et al reported transvaginal nephrectomy performed using a purpose-built multi-lumen operating platform [22]. Haber et al assessed the feasibility of pure NOTES transvaginal nephrectomy in a porcine model using NOTES-specific instrumentation without transabdominal ports [23].

In the field of nephron-sparing surgery, Crouzet et al presented their laboratory experience with NOTES renal cryoablation in pigs performed with either a transgastric or transvaginal approach [24]. Boylu et al assessed the feasibility of NOTES transgastric partial nephrectomy (PN) without hilar clamping [25].

In the pelvis, expanding the technique of holmium laser enucleation of the prostate (HoLEP), Humphreys et al reported their preliminary experience with the technical development of NOTES RP in a cadaver model [26]. A pure NOTES approach for partial cystectomy has also recently been described in a porcine model by using either a transurethral or a transgastric approach [27].

Note that most of the above-mentioned reports included the use of acute porcine models. Thus, the postoperative effects of an elective viscerotomy have not been fully studied so far and therefore remain to be clarified.

\subsubsection{Laparoendoscopic single-site surgery: access and urologic procedures}

LESS access can be obtained either by performing a single skin and fascial incision through which a single multichannel access platform is placed (single port) or by placing several low-profile ports through separate fascial incisions (single site) [2]. The access point can be umbilical or extraumbilical.

Since the pioneering report by Raman et al on LESS for nephrectomy in pigs [12], a limited number of experimental studies have been published on LESS urologic procedures. Barret et al reported their experience with LESS extraperitoneal RP in a cadaver model [28]. More recently, Boylu et al determined the feasibility, instrumentation, and learning curve for LESS PN in a pig model [29].

\subsection{Currently available tools for urologic applications}

Despite evolving from the concepts and techniques of standard laparoscopy, LESS defies some basic laparoscopic principles, including instrument and external port spacing to decrease clashing. New laparoscopic access devices, optics, and instrumentation specifically designed for successfully facilitating LESS have been developed in the last few years [13,30-32] (Table 3 ).

\subsubsection{Access devices}

Multichannel ports can be employed during LESS as one approach to access. These devices allow for the insertion of instruments and a camera and involve a single fascial incision.

The TriPort port (Olympus, Tokyo, Japan), previously known as R-port, represented the first multi-instrument port designed specifically for LESS [33]. The SILS port (Covidien, Mansfield, MA, USA) is foam port that expands after insertion to prevent air leakage. The GelPOINT port (Applied Medical, Rancho Santa Margarita, CA, USA) is similar to the already-available GelPort port but with a smaller diameter. The AirSeal port (SurgiQuest, Orange, CT, USA) maintains pneumoperitoneum by creating an air vortex [34].

A recognized disadvantage of LESS when using this approach to access is related to the costs of these SPA platforms. Reusable devices, such as the X-CONE and ENDOCONE ports (Karl Storz, Tuttlingen, Germany), might represent an attractive option, but specific cost comparisons have not yet been reported.

Alternatively, LESS access can be obtained with the use of several low-profile, small-diameter head trocars (such as AnchorPort trocars [SurgiQuest, Orange, CT, USA], Pediport trocars [Covidien, Mansfield, MA, USA], and Hunt trocars [Apple Medical, Marlborough, MA, USA]) with separate fascial stab incisions (single site). These devices can be clustered within a single incision or through three separate stab incisions clustered within the umbilical ring.

Initial clinical experience with LESS nephrectomy using a homemade single-port device was also reported [35]. An Alexis wound retractor was inserted at the umbilicus, and a surgical glove was installed over the outer ring of the wound retractor. About 3-4 fingers of the glove were cut, and one $10-\mathrm{mm}$ and two or three $5-\mathrm{mm}$ trocars were placed. The fingers of the glove were secured to the end of the trocars with a rubber band and fixed to the outer ring of the wound retractor. The device provided adequate range of motion and enough flexibility in port placement for LESS.

\subsubsection{Instruments}

When instruments are inserted in parallel through the same site, clashing and decreased maneuverability represent major limitations. Articulating instruments have been developed to allow the surgeon's hands to be positioned apart from each other while maintaining the tips of the instruments still focused on the same point inside the abdomen. A combination of conventional and flexible (articulating) instruments provides improved intraoperative ergonomics [13,30-32]. Traditional rigid, straight instruments have also been used for LESS. Branco et al evaluated LESS urologic surgery using conventional laparoscopic instruments and ports, claiming that articulating instruments might be not strictly necessary [36].

Pre-bent instruments have been introduced with the aim of minimizing instrument clashing outside the port, providing triangulation in the operative field and better force application at instrument tip during dissection [37]. They are also cost-effective, because they are reusable compared to the single-use disposable flexible instruments. Stolzenburg et al recently performed a comparative evaluation in a dry and animal laboratory of conventional, flexible, and pre-bent instruments in an attempt to elucidate instrument effectiveness and maneuverability [38]. Pre-bent instruments proved to be less time-consuming and provided better maneuverability.

With the rise of LESS and NOTES, needlescopic instruments have also been re-discovered, as they can be 
Table 3 - Toolbox for laparoendoscopic single-site surgery: access devices, instruments, and optics

\begin{tabular}{|c|c|c|}
\hline Category & Name & Main features \\
\hline \multirow[t]{9}{*}{ Access device } & TriPort (Olympus) & $\begin{array}{l}\text { Allows three instruments to be passed into the abdomen through one small }(10-25-\mathrm{mm}) \\
\text { incision. Consists of a boot containing one } 12-\mathrm{mm} \text { and two } 5-\mathrm{mm} \text { gel valves. Two luer } \\
\text { connectors for insufflation and smoke evacuation. Introducer to aid placement. }\end{array}$ \\
\hline & SILS port (Covidien) & $\begin{array}{l}\text { Foam port inserted through a } 2 \text {-cm fascial incision, expanding after insertion to prevent air } \\
\text { leakage. Small holes within the foam accommodate } 5-\mathrm{mm} \text { or } 12-\mathrm{mm} \text { trocars. }\end{array}$ \\
\hline & GelPOINT (Applied Medical) & $\begin{array}{l}\text { Similar to the already-available GelPort but smaller, without perforations in the gel cap, the } \\
\text { GelPOINT has an insufflation port on the side of the device and a suture attached to the wound } \\
\text { protection apparatus to allow for easier removal. }\end{array}$ \\
\hline & AirSeal (SurgiQuest) & $\begin{array}{l}\text { No physical seal, AirSeal maintains pneumoperitoneum by creating an air vortex. Multiple } \\
\text { instruments to fit through one large opening in the trocar. }\end{array}$ \\
\hline & X-CONE (Karl Storz) & $\begin{array}{l}\text { The X-CONE has a main metallic conical structure to which a plastic cap is attached. Four } \\
\text { instrument ports and an insufflation port are available. Open Hassan technique for insertion } \\
\text { can be used; the device is reusable. }\end{array}$ \\
\hline & ENDOCONE (Karl Storz) & $\begin{array}{l}\text { The ENDOCONE allows ergonomic placement of the valves for multiple telescope and } \\
\text { instrument access, has a rigid seal cap, and is reusable. }\end{array}$ \\
\hline & $\begin{array}{l}\text { Single Site Laparoscopy access system } \\
\text { (Ethicon Endo-Surgery) }\end{array}$ & $\begin{array}{l}\text { Ethicon's system has a low-profile seal cap, including two } 5-\mathrm{mm} \text { seals and one } 15-\mathrm{mm} \text { seal, } \\
\text { and } 360^{\circ} \text { seal cap rotation to allow for reorientation of instrumentation throughout the } \\
\text { procedure without necessitating instrument exchanges. }\end{array}$ \\
\hline & OCTO-Port (Dalim SurgNet) & $\begin{array}{l}\text { The OCTO-Port consists of an inferior base plate that sits under the skin edge in the } \\
\text { peritoneum, an external disc with self-retractor, and a transparent silicone cover with three or } \\
\text { four channels. }\end{array}$ \\
\hline & SPIDER Surgical System (TransEnterix) & $\begin{array}{l}\text { The SPIDER Surgical System is composed of two primary assemblies: a platform access device } \\
\text { and a stabilizer with a bed clamp. It includes an insertion trocar covered by a retractable } \\
\text { sheath and nose cone and four working channels. }\end{array}$ \\
\hline \multirow[t]{4}{*}{$\begin{array}{l}\text { Articulating } \\
\text { instruments }\end{array}$} & $\begin{array}{l}\text { RealHand High Dexterity (HD) } \\
\text { instruments (Novare Surgical Systems) }\end{array}$ & $\begin{array}{l}\text { HD technology consists of } 5-\mathrm{mm} \text { hand instruments in which the handle is connected to the tips } \\
\text { by several cables, allowing for } 360^{\circ} \text { reticulation mimicking the hand's movement. There is a } \\
\text { significant learning curve. }\end{array}$ \\
\hline & $\begin{array}{l}\text { Autonomy Laparo-Angle instruments } \\
\text { (Cambridge Endoscopic Devices) }\end{array}$ & $\begin{array}{l}\text { These instruments can move in a } 360^{\circ} \text { plane and be locked into position. The large, bulky } \\
\text { handle remains suboptimal. }\end{array}$ \\
\hline & Roticulator (Covidien) & $\begin{array}{l}\text { A less expensive alternative already used in standard laparoscopy. However, the Roticulator } \\
\text { offers a limited degree of freedom, as the articulation is in one plane only. }\end{array}$ \\
\hline & SILS Stitch instrument (Covidien) & $\begin{array}{l}\text { This instrument offers the toggle-activated needle-passing technology already available for } \\
\text { conventional laparoscopy with the additional features of distal shaft articulation, needle jaw } \\
\text { tip rotation, and additional shaft length. }\end{array}$ \\
\hline \multirow{4}{*}{$\begin{array}{l}\text { Pre-bent } \\
\text { instruments } \\
\text { Needlescopic } \\
\text { instruments }\end{array}$} & $\begin{array}{l}\text { S-PORTAL series (Karl Storz) } \\
\text { HiQ LS hand instruments (Olympus) }\end{array}$ & $\begin{array}{l}\text { Pre-shaped, rigid instruments, with different profiles, S-PORTAL devices are reusable but offer } \\
\text { fewer degrees of freedom. }\end{array}$ \\
\hline & MiniSite series (Covidien) & These instruments offer a 2-mm miniport and minishears. \\
\hline & MiniLap series (Stryker) & $\begin{array}{l}\text { These instruments offer a } 2.3 \text {-mm diameter, clamps with different tips, and percutaneous } \\
\text { access (trocarless). }\end{array}$ \\
\hline & Minilaparoscopy series (Karl Storz) & $\begin{array}{l}\text { These instruments offer a } 3-\mathrm{mm} \text { diameter and } 36-\mathrm{cm} \text { length. They are to be used with a } \\
3.5-\mathrm{mm} \text { trocars with a silicone leaflet valve. }\end{array}$ \\
\hline \multirow[t]{4}{*}{ Optics } & EndoEYE LS (Olympus) & $\begin{array}{l}\text { This camera offers a high-definition, } 5-\mathrm{mm}, 30^{\circ} \text { digital scope. The control section can be } \\
\text { bent by as much as } 90^{\circ} \text {, and the system offers integrated light and camera, with a } \\
\text { CCD chip on the tip. }\end{array}$ \\
\hline & EndoEYE LTF VP (Olympus) & $\begin{array}{l}\text { This camera offers a high-definition, } 5-10-\mathrm{mm}, 0^{\circ} \text { digital scope with a deflectable tip } \\
\left(100^{\circ} \text { angulation). It has integrated light and camera and a CCD chip on the tip. }\right.\end{array}$ \\
\hline & IDEAL EYES (Stryker) & $\begin{array}{l}\text { This camera comes in } 10 \mathrm{~mm} \text {, with a friction-assist brake, integrated light cable, and over } \\
100^{\circ} \text { of flexion in all directions. }\end{array}$ \\
\hline & EndoCAMeleon (Karl Storz) & $\begin{array}{l}\text { This device is a } 10 \text {-mm laparoscope with variable direction (between } 0^{\circ} \text { and } 120^{\circ} \text { ) of view } \\
\text { camera by means of a chip rotating within the tip. }\end{array}$ \\
\hline
\end{tabular}

introduced through a small puncture that requires no formal closure, thus pursuing the philosophy of scarless surgery. Recently, a specific set for minilaparoscopy (Karl Storz, Tuttlingen, Germany) has been made available.

\subsubsection{Optics}

A key problem with conventional laparoscopes is that they have a large extracorporeal profile, with a light cable exiting at $90^{\circ}$. This configuration leads to clashing of instruments and the camera during LESS. Thus, the ideal telescope for LESS should remove the light cord and camera head from the operative field. Low-profile camera systems have been introduced for this purpose [15,30-32].
Articulating laparoscopes, such as the EndoEYE (Olympus, Tokyo, Japan) or the IDEAL EYES (Stryker, Kalamazoo, MI, USA), represent additional tools for the single-port armamentarium. One issue with articulating scopes is the plastic casing that covers the flexible part of the tip, which tends to degrade over time. The camera chip in the $10-\mathrm{mm}$ EndoCAMeleon (Karl Storz, Tuttlingen, Germany) scope rotates within the tip, eliminating the need for the plastic casing while still giving surgeons the multidirectional view they need to operate. Moreover, $5-\mathrm{mm}, 30^{\circ}$, extra-long telescopes have been developed and marketed for LESS. The extra length removes the camera head and light cord from the operative field. 


\subsection{Urologic laparoendoscopic single-site surgery: current clinical evidence}

\subsubsection{Kidney and adrenal surgery}

Rane et al presented an early series of five LESS simple nephrectomies [39]. More recently, Han et al reported 14 LESS simple nephrectomies in patients with a benign nonfunctioning kidney, including four cases resulting from genitourinary tuberculosis [35] (Table 4).

Initially, investigators remained careful and selective in applying LESS for oncologic conditions. In their initial report, Raman et al included one patient with a $4.5-\mathrm{cm}$ kidney cancer mass [12]. Soon after, Kaouk et al reported a radical nephrectomy for a $5-\mathrm{cm}$ left renal mass in their initial LESS series [40]. Subsequently, Ponsky et al described a LESS radical nephrectomy for an 8-cm renal tumor with intact specimen extraction [41].

Stolzenburg et al more recently reported their LESS radical nephrectomy technique in a series of 10 non-obese patients (two right-sided and eight left-sided tumors; diameter $4-8 \mathrm{~cm}$ ) [42]. In this case, a multichannel port was inserted through a transumbilical incision, and a standard laparoscopic transperitoneal nephrectomy was performed. Only one bleeding complication occurred.

Laparoscopic PN represents a technically demanding procedure under the best of circumstances. LESS PN has been reported so far by few groups. Aron et al reported five selected cases (inclusion criteria: body mass index [BMI] $\leq 30$, tumour size $<7 \mathrm{~cm}$, anterior exophytic tumour at the interpolar or lower pole location, no prior abdominal surgery) [43]. In all cases, a 2-mm grasper was used through a separate entry to assist in suture closure of the renal defect. Median warm ischemia time was $20 \mathrm{~min}$. One patient had postoperative bleeding and pulmonary embolism. In contrast, Rais-Bahrami et al reported their initial three LESS PNs, all of which were performed by a pure LESS approach with no accessory trocars [44].

Kaouk and Goel reported their experience with seven LESS PNs, including the use of robotic assistance in two cases [45]. One patient required conversion to conventional laparoscopy. A focally positive margin on final pathology was found in one case. The same authors reported the first series of single-port kidney cryotherapy [46]. Patients with localized small renal mass $(<3 \mathrm{~cm})$ ineligible for partial or radical nephrectomy were included. The procedure was performed transperitoneally in two patients with anterior tumors and retroperitoneoscopically in the other four patients with posterior tumors. Despite significant instrument clashing, cryotherapy was feasible without intraoperative complication.

Laparoscopic living-donor nephrectomy has become an established alternative to open surgery, with equivalent allograft outcomes, quicker recovery, and superior cosmesis [47]. Gill et al first reported the successful completion of single-port transumbilical live-donor nephrectomy [48]. The authors used the R-Port, achieving pneumoperitoneum by inserting an additional 2-mm Veress needle port. This port was used to insert a needlescopic grasper to aid tissue handling. All four cases were successfully accomplished

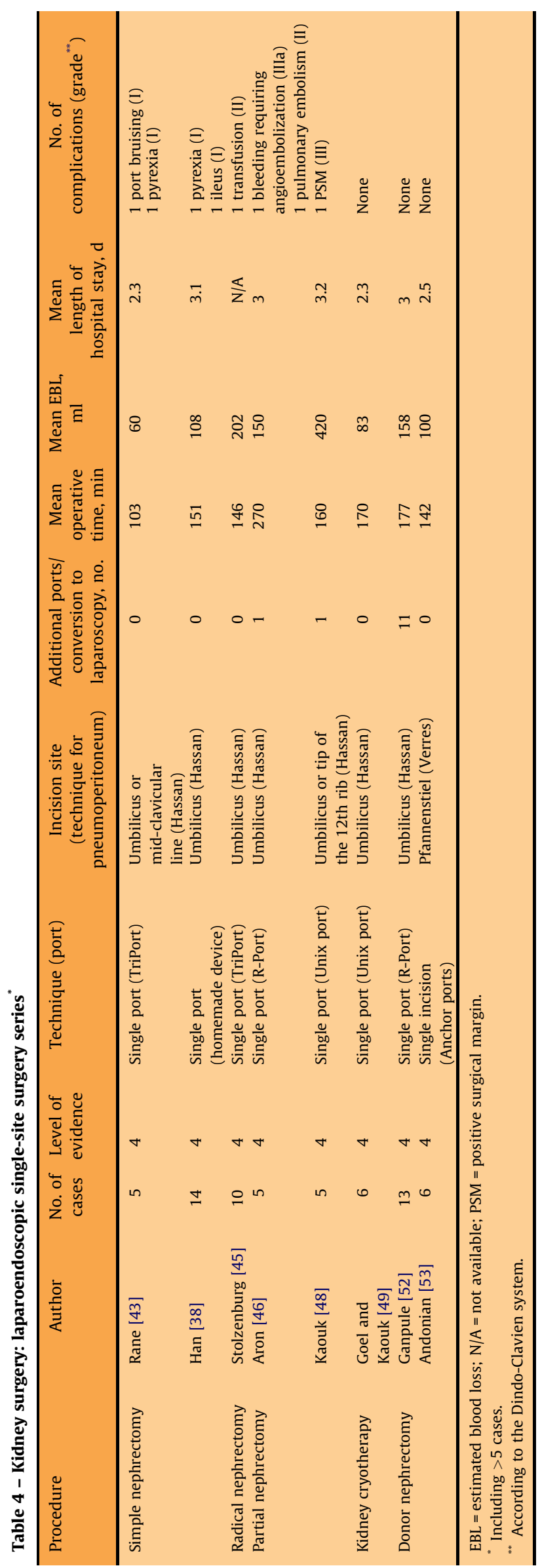


without complication. The donor kidney was pre-entrapped and extracted transumbilically with a 3-4-cm incision. Mean warm ischemia time was $6.2 \mathrm{~min}$. Each allograft functioned immediately on transplantation.

Ganpule et al from India reported a series of 13 patients undergoing LESS donor nephrectomy [49]. Note that in 11 of the 13 cases, an extra 3- or 5-mm port was used. Mean warm ischemia time was $6.8 \mathrm{~min}$. Urine output was prompt in all cases. The authors claimed proper selection of donors (low BMI, shorter xiphoid-to-umbilicus length, no vascular anomalies) as the key to successful completion of the procedure.

Andonian et al described a series of six LESS donor nephrectomies. They used three $5-\mathrm{mm}$ ports placed in a triangular manner through a 5-cm mini-Pfannenstiel incision [50]. After the kidney was placed in the entrapment sac, the anterior rectus fascia between the two midline ports was incised and the kidney removed. The procedure was successfully performed in all patients, with a median warm ischemia time of $5 \mathrm{~min}$.

Increasing experience and the proven safety and feasibility of LESS have allowed for the expansion of indications to include complex reconstructive procedures. Desai et al first reported on the feasibility of performing single-port transumbilical advanced laparoscopic reconstructive surgery in six patients. A 2-mm Veress needle port, inserted through a skin needle puncture, was used to create the pneumoperitoneum and to selectively insert a needlescopic grasper to assist in suturing [51]. Recently, Cindolo et al described a LESS adrenalectomy by using a TriPort port inserted through a 3-cm subcostal incision [52].

Finally, two institutions recently reported their cumulative kidney surgery series. Rais-Baharami et al presented a total of 11 renal LESS procedures [44]-all performed through a single operative site using a 5-mm flexible-tip laparoscope and articulating instruments. Ryu et al described urologic LESS surgery via the retroperitoneal approach using the Alexis wound retractor with flexible laparoscopic instrumentation [53]. Fourteen patients underwent LESS for various indications, including adrenalectomy and nephroureterectomy. All cases were completed without conversion to standard laparoscopic or open surgery and without major complications.

All of the above-mentioned series clearly show that the entire range of LESS kidney and adrenal surgical procedures is feasible-at least in the hands of experienced laparoscopic surgeons in tertiary care settings. Despite encouraging early clinical experience, if and how much LESS will actually affect current practice in the field of upper urinary tract surgery remains to be determined, given its inherent technical challenges.

\subsubsection{Pelvic surgery}

Kaouk et al presented an initial feasibility study on LESS RP [54]. Four T1c prostate cancer patients, with BMI $<35$, were included (Table 5). Flexible and pre-bent instruments were inserted through a Uni-X umbilical port (Advanced Surgical Concepts, Bray, Ireland). An endoscopic camera with a flexible tip provided visualization of the operative field, and

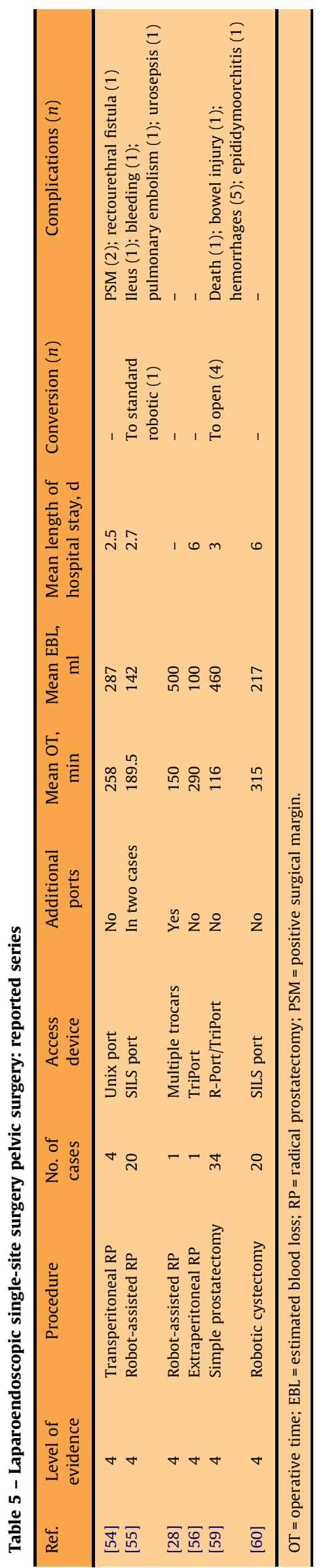


extracorporeal knot tying was performed for the anastomosis, which required $1.1 \mathrm{~h}$. Positive surgical margins (PSM) were detected in two patients with extracapsular extension. Two months postoperatively, a recto-urethral fistula was diagnosed in one case (Clavien grade IIIb complication). Challenges of the technique were mostly related to ergonomics and intracorporeal suturing and to limitations in available instrumentation. After this initial series, the same group started an experience with robotassisted LESS RP, with more favorable outcomes [55]. Rabenalt et al also reported the first clinical experience with a LESS extraperitoneal RP [56].

Based on available data, although feasible, LESS RP should be regarded as a procedure with major technical limitations. The application of robotics has been shown to overcome some of these downsides, and early experience with robotic LESS RP has been encouraging. Besides these initial feasibility studies, further investigation is needed to evaluate the oncologic and functional outcomes of the procedure and to compare them with current standard RP techniques.

Desai et al reported their early experience with the single-port transvesical enucleation of the prostate (STEP) technique in three patients with large-volume benign prostatic hypertrophy (BPH). The R-port device was introduced percutaneously into the bladder through a $2.5-\mathrm{cm}$ incision under cystoscopic guidance [57]. Sotelo and his group also detailed their technique of the simple prostatectomy using a single multilumen port [58]. More recently, these two groups of investigators jointly presented their cumulative multi-institutional series of STEP in 34 patients [59]. Digital adenoma enucleation was used in 19 (55\%) cases. There was one death (Clavien grade V complication) from postoperative bleeding from uncontrolled coagulopathy in a Jehovah's Witness patient who refused transfusions. Other major complications were one bowel injury (grade IIIb) and five hemorrhages (grade II-IIIb).

Overall, when looking at the outcomes of single-port surgery for BPH treatment, it can be wisely concluded that this technique is not likely to have a large impact in the surgical treatment of $\mathrm{BPH}$, given other currently effective available options (ie, HoLEP, photoselective vaporization, bipolar transurethral resection of the prostate [TURP]) that are already performed through a "natural orifice" (transurethrally).

The first series of LESS radical cystectomy and bilateral pelvic lymph node dissection in three patients was recently reported by Kaouk et al. [60]. Locally advanced disease, previous abdominal or pelvic surgery or radiation therapy (RT), or those desiring orthotopic reconstruction were excluded. All the procedures were completed successfully without the need for extraumbilical ports. All patients underwent extracorporeal urinary diversion by way of extension of the umbilical port site. Mean operative time was $315 \mathrm{~min}$, and blood loss was minimal. Pathology revealed negative margins and negative lymph node involvement (mean number of nodes: 16). All patients were discharged within $1 \mathrm{wk}$ with minimal postoperative pain. At a minimum of $2 \mathrm{yr}$ of follow-up, no evidence of recurrent or metastatic disease was detected. Despite its demonstrated feasibility, this procedure should be regarded as investigational; its role remains to be undetermined.

\subsubsection{Cumulative series}

To date, three large series of urologic LESS procedures have been reported. White et al reported the Cleveland Clinic experience with the first 100 LESS urologic procedures [61]. Specifically, 74 patients underwent LESS renal surgery, and 26 patients underwent LESS pelvic surgery. Six patients required conversion to standard laparoscopy, none to open surgery. The overall complication rate was $11 \%$.

A bi-center experience with 100 LESS procedures was reported by Desai et al that included simple, partial, radical, and donor nephrectomies, nephroureterectomy, adrenalectomy, pyeloplasty, transvesical simple prostatectomy, and others [62]. All of the procedures were performed using a single-port device and a varying combination of standard and specialized bent/articulating laparoscopic instruments. LESS procedures accounted for $15 \%$ of all laparoscopic procedures performed by the authors for similar indications. The addition of one or more ports was needed in six cases, and conversion to open surgery was necessary in four cases, with an overall conversion rate of $10 \%$. One death occurred following simple prostatectomy. The overall complication rate was $14 \%$.

Recently, Jeon et al report their cumulative experience with 50 patients undergoing LESS using a homemade single-port device [63]. Of the patients, 34 underwent conventional LESS, while 16 underwent robotic LESS, including PN in 11 cases, nephroureterectomy in 3 cases, and simple and radical nephrectomy in 1 case each. Four intraoperative complications occurred, including two bowel serosal tears, diaphragm partial tearing, and conversion to open radical nephrectomy. One case of postoperative bleeding was managed by transfusion.

Based on these three large series, LESS surgery has shown to be feasible, albeit technically challenging and, for a broad range of urologic applications, offering high patient satisfaction and shortened convalescence. Outcomes seem to be comparable to conventional laparoscopy. Proper patient selection is important for minimizing complication and conversion rates.

\subsubsection{Laparoendoscopic single-site surgery versus standard}

laparoscopy: comparative outcomes

Comparative series between conventional laparoscopy and LESS have recently become available (Table 6).

Raman et al were the first to report a case-control study comparing LESS with conventional laparoscopy [64]. They compared 11 LESS with 22 laparoscopic nephrectomies. According to the authors, the superiority of LESS over standard laparoscopic nephrectomy was "limited" to a mere subjective cosmetic advantage, even if this advantage was not specifically measured or quantified.

Considering that in this study, half of the LESS patients had a nephrectomy for malignancy, necessitating extension of the initial umbilical incision for specimen extraction, the 
Table 6 - Laparoendoscopic single-site surgery versus laparoscopy: reported outcomes from case-control comparative series

\begin{tabular}{|c|c|c|c|c|c|c|c|c|c|c|}
\hline Ref. & $\begin{array}{l}\text { Level of } \\
\text { evidence }\end{array}$ & Procedure & $\begin{array}{c}\text { LESS } \\
\text { access }\end{array}$ & No. of cases & $\begin{array}{c}\text { Conversion, } \\
\text { no. }\end{array}$ & $\begin{array}{l}\text { Median } \\
\text { OT, min }\end{array}$ & $\begin{array}{l}\text { Median } \\
\text { EBL, ml }\end{array}$ & $\begin{array}{l}\text { Median length of } \\
\text { hospital stay, } \mathrm{h}\end{array}$ & Analgesics & $\begin{array}{c}\text { Complication } \\
\text { rate, \% }\end{array}$ \\
\hline \multirow[t]{2}{*}{ [64] } & 3 & Simple and & Single incision & 11 LESS & 0 & 122 & 20 & 49 & $8^{*}$ & 0 \\
\hline & & radical nephrectomy & & 22 laparoscopic & 0 & 125 & 100 & 53 & $15^{*}$ & 0 \\
\hline$p$ value & & & & & & NS & 0.001 & NS & NS & NS \\
\hline \multirow{2}{*}{ [65] } & 3 & Pyeloplasty"* & Single incision ${ }^{* * *}$ & 15 LESS & $1^{\dagger}$ & 202 & 35 & 77 & $34^{*}$ & 33 \\
\hline & & & & 28 laparoscopic & 0 & 257 & 85 & 74 & $38^{*}$ & 21 \\
\hline$p$ value & & & & & & $<0.001$ & 0.002 & NS & NS & NS \\
\hline \multirow[t]{2}{*}{ [67] } & 3 & Adrenalectomy & Single port & 9 LESS & 1 & 169.2 & 177.8 & 77 & $0.9^{\dagger \dagger}$ & 11 \\
\hline & & & & 17 laparoscopic & 1 & 144.5 & 204.7 & 84 & $1.9^{\dagger \dagger}$ & 6 \\
\hline$p$ value & & & & & & NS & NS & NS & 0.047 & NS \\
\hline & 3 & Simple nephrectomy & Single port ${ }^{t \dagger \dagger}$ & 11 LESS & 0 & 151 & 51 & 32 & $364^{\ddagger}$ & 20 \\
\hline & & & & 10 laparoscopic & 0 & 165 & 68 & 26 & $231^{\ddagger}$ & 10 \\
\hline$p$ value & & & & & & NS & NS & NS & NS & NS \\
\hline \multirow[t]{3}{*}{ [69] } & 3 & Sacrocolpopexy"* & Single port & 10 LESS & 0 & 162 & 47 & 36 & NR & 0 \\
\hline & & & & 10 laparoscopic & 0 & 151 & 65 & 38 & & 0 \\
\hline & & & & 10 robotic & 0 & 150 & 87 & 38 & & 0 \\
\hline$p$ value & & & & & & & NS & NS & NS & NS \\
\hline \multirow[t]{2}{*}{ [68] } & 3 & Kidney cryoablation** & Single-port & 5 LESS & 0 & 174 & 75 & 33 & NR & 0 \\
\hline & & & retroperitoneal & 5 laparoscopic & 0 & 120 & 100 & 43 & & 0 \\
\hline$p$ value & & & & & & $<0.001$ & NS & NS & NS & NS \\
\hline \multicolumn{11}{|c|}{$\begin{array}{l}\text { LESS = laparoendoscopic single-site surgery; OT = operative } \\
\text { Morphine equivalents (mg). } \\
\text { Mean values expressed. } \\
\text { Additional 5-mm trocar systematically used. } \\
\text { Excluded from the analysis. } \\
{ }^{\dagger} \text { Number of days of IV patient-controlled anesthesia use. } \\
{ }_{\dagger+} \text { Additional 5-mm trocar in one case. } \\
\$ \text { mg (drug not specified). }\end{array}$} \\
\hline
\end{tabular}


same group of investigators speculated that this may have blunted the potential benefit of LESS. Therefore, they addressed a reconstructive procedure, such as pyeloplasty. Fourteen patients undergoing LESS pyeloplasty were matched 2:1 with regard to age and side of surgery to a previous cohort of 28 patients who underwent laparoscopic pyeloplasty [65]. Suturing was aided through a 5-mm instrument placed in the eventual drain site. Interestingly, median operative times and median estimated blood loss (EBL) were significantly lower in patients undergoing LESS. The authors claimed that the 50-ml difference in blood loss was not likely to be clinically significant and was probably related to the inevitable inaccuracies in intraoperative measurement. Regarding the operating room (OR) time, they partially attributed the difference to the fact that $75 \%$ of control patients underwent cystoscopy with retrograde stent placement, which requires repositioning of the patient and additional equipment compared to the antegrade stent placement performed in all LESS cases. In addition, more patients in the laparoscopy cohort had previous endoscopic management of their ureteropelvic junction, which may have made dissection more difficult.

Raybourn et al matched a total of 11 patients undergoing LESS simple nephrectomy with a group of 10 patients who previously underwent simple laparoscopic nephrectomy [66]. All LESS procedures were completed with no intraoperative complications. Postoperative complications included fever and port site bruising in two patients. No difference was detected in the analgesia requirement between matched groups. The authors claimed an obvious cosmetic advantage, even if it was not specifically quantified.

Jeong et al recently described the first study comparing LESS to laparoscopy in the treatment of benign adrenal adenoma [67]. Nine patients undergoing LESS adrenalectomy were compared with 17 matched patients undergoing conventional laparoscopic adrenalectomy. Postoperative pain, as measured by the mean number of days of intravenous (IV) patient-controlled anesthesia use, was significantly lower in the LESS group. LESS adrenalectomy was comparable to the conventional laparoscopic approach in terms of perioperative parameters. The authors claimed a higher cosmetic outcome, even if this outcome was not specifically measured.

White et al retrospectively compared single-port retroperitoneal cryoablation with standard retroperitoneoscopy [68]. Subjective evaluation by the patients of postoperative pain was significantly in favor of the LESS approach, but the amount of analgesics used in each group was not reported, partially mitigating the clinical significance of this finding.

The same group from the Cleveland Clinic performed a retrospective cohort study to determine the efficacy and safety of LESS abdominal sacral colpopexy for the treatment of female pelvic organ prolapse. Despite a limited postoperative follow-up, the procedure appeared to be comparable to the laparoscopic and robotic approaches in terms of efficacy but with superior cosmesis [69].

Two retrospective matched-pair comparison of LESS to standard laparoscopic live-donor nephrectomy have been recently reported [70,71] (Table 7). Canes et al performed this LESS procedure through an intra-umbilical multichannel port, using a 5-mm rigid laparoscope with integrated camera head, with standard and curved/articulating instruments [70]. The kidney was extracted through a slightly extended umbilical incision. Mean warm ischemia time was significantly longer in the LESS group, even if allograft function was comparable between groups at 3 mo. Patients undergoing LESS donor nephrectomy had similar

Table 7 - Laparoendoscopic single-site surgery versus laparoscopic living donor nephrectomy: comparative outcomes*

\begin{tabular}{|c|c|c|c|c|}
\hline & \multicolumn{2}{|c|}{ Canes et al. [73] } & \multicolumn{2}{|c|}{ Andonian et al. [74] } \\
\hline & LESS & Laparoscopy & LESS & Laparoscopy \\
\hline Cases, no. & 17 & 17 & 6 & 6 \\
\hline Age, yr & 40 & 43 & 46 & 28 \\
\hline BMI, $\mathrm{kg} / \mathrm{m}^{2}$ & 25 & 25.6 & 28 & 25 \\
\hline Allograft volume, $c^{3}$ & 169 & 177 & 175 & 146 \\
\hline \multicolumn{5}{|l|}{ Side, no.: } \\
\hline Right & 0 & 0 & 1 & 3 \\
\hline Left & 17 & 17 & 5 & 3 \\
\hline Complex anatomy, no. & 5 & 4 & 1 & 1 \\
\hline OR time, min & 240 & 222 & 142 & 117 \\
\hline Warm ischemia time, min & $6^{* *}$ & $3^{* *}$ & 5 & 5 \\
\hline $\mathrm{EBL}, \mathrm{ml}$ & 50 & 100 & 100 & 150 \\
\hline Length of hospital stay, $d$ & 3 & 3 & 2 & 2 \\
\hline Complications, no. (Clavien grade) & 2 (I; IIIb) & 0 & 0 & $1(\mathrm{I})$ \\
\hline Morphine equivalent, mg & 97 & 98 & 83 & 42 \\
\hline VAS at discharge & 3.5 & 1 & 0 & 2 \\
\hline Days on oral pills & $4^{* *}$ & $14^{* *}$ & $\mathrm{~N} / \mathrm{A}$ & $\mathrm{N} / \mathrm{A}$ \\
\hline Days to return to work & $14^{* *}$ & $49^{* *}$ & & \\
\hline Days to $100 \%$ recovery & $26^{* *}$ & $60^{* *}$ & & \\
\hline $\begin{array}{l}\text { LESS = laparoendoscopic single-site } \\
\text { assessed. } \\
\text { For continuous variables, values } \\
\text { Statistically significant difference }\end{array}$ & mass ind & & & \\
\hline
\end{tabular}


in-hospital analgesic requirements and mean visual analog scale (VAS) scores at discharge, but their convalescenceassessed by considering days on oral pain medication, days off work, and days to full physical recovery-was faster.

Andonian et al compared their LESS Pfannenstiel donor nephrectomy with a series of standard laparoscopic donor nephrectomy [71]. In the LESS group, there were no conversions to laparoscopy or open surgery. The laparoscopic group included more right-sided patients and more venous anomalies. No significant difference was found between the groups in terms of operative time, warm ischemia time, EBL, length of hospital stay, or total morphine equivalents. A patient in the laparoscopic group developed a wound infection. There were no perioperative complications in the LESS group. Postoperative VAS scores were lower in the LESS group but did not reach statistical significance.

So far, all comparative studies have been limited by small numbers, their nonrandomized design, their retrospective nature, and the lack of standardization in the assessment of postoperative outcomes. Overall, these series have shown a non-inferiority of LESS over conventional laparoscopy in terms of perioperative outcomes, with an encouraging trend toward less postoperative pain and better cosmesis.

\subsection{Clinical natural orifice transluminal endoscopic surgery: hybrid and pure transvaginal nephrectomy}

Investigators have largely combined NOTES with a conventional laparoscopic approach (hybrid NOTES technique) [2] (Table 8). Hybrid NOTES nephrectomy in humans was first described by Branco et al. [72], who reported a case of transvaginal right simple nephrectomy for nonfunctional kidney in a 23-yr-old woman. An endoscope using vaginal access and two additional 5-mm trocars in the abdomen were used. Total procedure time was $170 \mathrm{~min}$, and EBL was $350 \mathrm{c}^{3}$.In this case, vaginal access was only used to accommodate optics and for specimen extraction.

Alcaraz et al presented their early series of transvaginal NOTES-assisted laparoscopic nephrectomy with T1-T3a kidney cancer [73]. Vaginal access was only used to insert a deflectable camera, whereas two additional abdominal trocars were used as main working ports for instrumentation. One patient had a colon injury. Difficulties in organ retrieval occurred in a patient with a higher BMI.

A multi-institutional experience with hybrid NOTES transvaginal nephrectomy in four patients was reported by Sotelo et al. [74]. The first three cases were electively converted to standard laparoscopy because of rectal injury during vaginal entry, failure to progress, or intraoperative bleeding. One patient was successfully operated without conversion to standard laparoscopy. A single multichannel port was placed transumbilically through which dissection and hilar division were performed. The patient required readmission and drainage of an intra-abdominal abscess. The authors claimed that their series was different from the Branco and Alcaraz series in that the transvaginal approach was used to perform the majority of intraoperative steps, and the patient had no extra-umbilical skin incisions whatsoever. Nevertheless, they concluded that although feasible, NOTES transvaginal nephrectomy requires significant refinement in operative technique and instrumentation.

To further minimize the use of accessory transabdominal ports, Kaouk et al at the Cleveland Clinic successfully performed a transvaginal NOTES nephrectomy on a 57-yrold woman with a nonfunctioning right kidney [75]. The procedure was successfully completed, with all of the operative steps performed transvaginally. Pelvic adhesions from a prior hysterectomy necessitated the use of only one 5-mm umbilical port during vaginal port placement and for retraction of the ascending colon during division of the renal hilum. No intraoperative complications occurred. Operative time was $307 \mathrm{~min}$, of which $124 \mathrm{~min}$ were dedicated to vaginal port placement and $183 \mathrm{~min}$ were dedicated to the procedure. Hospital stay was $<24 \mathrm{~h}$, with return to normal activities within $1 \mathrm{wk}$.

Still, complete or pure NOTES should involve no transabdominal port placement at all. Shortly afterwards, the same group of investigators from the Cleveland Clinic was able to successfully perform the first pure NOTES transvaginal nephrectomy in a 58-yr-old woman who presented with an atrophic right kidney [9]. A blunt-tip trocar was introduced transvaginally into the peritoneal cavity. Using a standard flexible video gastroscope, the abdominal cavity was explored transvaginally, and minimal pelvic adhesions were encountered. A GelPort device was deployed across the vaginal incision. Two $10-\mathrm{mm}$ standard trocars and one 5-mm standard trocar were placed across the GelPort through which a 5-mm deflecting laparoscope and 45-cm articulating graspers and scissors were placed. After exposing the hilum, an endovascular stapler was fired across the renal vein and renal artery. The remaining posterior and upper pole attachments were taken down using an extra-long $(65-\mathrm{cm})$ monopolar J-hook. The kidney was brought out through the existing vaginal incision.

Limitations for vaginal access include age, gender, and previous pelvic or vaginal surgery. Moreover, the effects on sexual function and quality of life (QoL) remain to be determined. Investigators from Australia recently surveyed 300 women to establish their opinions with respect to NOTES surgery versus standard laparoscopic procedures. Interestingly, three-fourths of the women surveyed were neutral or unhappy about the prospect of a NOTES procedure, even it was stipulated that laparoscopy and NOTES had equivalent safety and efficacy. The effect of NOTES on sexual function was expressed as a particular concern by younger women [76]. In another report, Peterson et al surveyed 100 women, exploring their concerns and opinions regarding transvaginal surgery [77]. The majority of women (68\%) indicated that they would want a transvaginal procedure in the future because of decreased risk of hernia and decreased operative pain ( $90 \%$ and $93 \%$, respectively), while only $39 \%$ were concerned with the improved cosmesis of NOTES surgery. Of the women polled, nulliparous women and those under $45 \mathrm{yr}$ of age were significantly more often concerned with how transvaginal surgery may affect healthy sexual life and 
Table 8 - Natural orifice transluminal endoscopic surgery transvaginal nephrectomy: reported cases

\begin{tabular}{|c|c|c|c|c|c|c|c|c|c|c|c|c|}
\hline Author & $\begin{array}{l}\text { Hybrid } \\
\text { or pure }\end{array}$ & $\begin{array}{l}\text { Level of } \\
\text { evidence }\end{array}$ & Procedure & $\begin{array}{l}\text { No. of } \\
\text { cases }\end{array}$ & $\begin{array}{l}\text { Transvaginal } \\
\text { port }\end{array}$ & $\begin{array}{l}\text { Abdominal } \\
\text { ports (site) }\end{array}$ & Special instruments & $\begin{array}{l}\mathrm{OT} \\
\mathrm{min}\end{array}$ & $\begin{array}{c}\mathrm{EBL}, \\
\mathrm{ml}\end{array}$ & $\begin{array}{l}\text { Length of } \\
\text { hospital } \\
\text { stay, h }\end{array}$ & $\begin{array}{l}\text { Complications, } \\
\text { no. (Clavien } \\
\text { grade) }\end{array}$ & Comment \\
\hline Branco [72] & Hybrid & 4 & $\begin{array}{l}\text { Simple } \\
\text { nephrectomy }\end{array}$ & 1 & None & $2 \times 5 \mathrm{~mm}$ & $\begin{array}{l}\text { Flexible endoscope; } \\
\text { polypectomy snare }\end{array}$ & 170 & 350 & 12 & 0 & $\begin{array}{l}\text { First reported hybrid } \\
\text { NOTES nephrectomy }\end{array}$ \\
\hline Kaouk [75] & & 4 & $\begin{array}{l}\text { Simple } \\
\text { nephrectomy }\end{array}$ & 1 & $\begin{array}{l}\text { TriPort } \\
\text { and GelPort }\end{array}$ & $\begin{array}{l}1 \times 5 \text {-mm } \\
\text { (umbilicus) }\end{array}$ & $\begin{array}{l}\text { Gastroscope; } 5 \text {-mm } 0^{\circ} \\
\text { deflecting scope; articulating } \\
\text { graspers and scissors; extra- } \\
\text { long monopolar J-hook }\end{array}$ & 307 & 100 & 23 & 0 & $\begin{array}{l}\text { First virtually scarless } \\
\text { (no extraumbilical } \\
\text { incision) nephrectomy }\end{array}$ \\
\hline Alcaraz [73] & & 4 & $\begin{array}{l}\text { Radical } \\
\text { and simple } \\
\text { nephrectomy }\end{array}$ & 14 & $\begin{array}{l}10-\mathrm{mm} \\
\text { obese trocar }\end{array}$ & $\begin{array}{l}1 \times 10-\mathrm{mm} \\
\text { (lateral to } \\
\text { umbilicus) } \\
1 \times 5 \mathrm{~mm} \\
\text { (flank) }\end{array}$ & $\begin{array}{l}\text { Deflectable optic; LigaSure } \\
\text { (Covidien, Boulder, CO, USA) } \\
\text { device }\end{array}$ & $133^{*}$ & $111^{*}$ & $96^{*}$ & $\begin{array}{l}1 \text { colon } \\
\text { injury (IIIb) }\end{array}$ & $\begin{array}{l}\text { First cases with oncologic } \\
\text { indication but not within } \\
\text { the definition of NOTES } \\
\text { ( }>1 \text { abdominal } \\
\text { trocar used) }\end{array}$ \\
\hline Sotelo [74] & & 4 & $\begin{array}{l}\text { Radical } \\
\text { nephrectomy }\end{array}$ & 1 & TriPort & $\begin{array}{l}\text { TriPort } \\
\text { (umbilicus) }\end{array}$ & $\begin{array}{l}\text { 5-mm } 0^{\circ} \text { scope with flexible } \\
\text { tip; } 30^{\circ} \text { EndoEYE } \\
\text { laparoscope; ultrasonic } \\
\text { shears; extra-long } \\
\text { monopolar J-hook }\end{array}$ & 210 & 1 & 150 & $\begin{array}{l}1 \text { intra- } \\
\text { abdominal } \\
\text { collection } \\
\text { (IIIa) }\end{array}$ & $\begin{array}{l}\text { No extraumbilical incision; } \\
\text { dissection mostly } \\
\text { preformed transvaginally }\end{array}$ \\
\hline Kaouk [9] & Pure & 4 & $\begin{array}{l}\text { Simple } \\
\text { nephrectomy }\end{array}$ & 1 & $\begin{array}{l}\text { GelPort } \\
\text { and TriPort }\end{array}$ & None & $\begin{array}{l}\text { Gastroscope; } 5 \text {-mm } 0^{\circ} \\
\text { deflecting laparoscope; } \\
\text { articulating graspers and } \\
\text { scissors; extra-long } \\
\text { monopolar J-hook }\end{array}$ & 420 & 50 & 19 & 0 & $\begin{array}{l}\text { First-ever performed } \\
\text { pure NOTES nephrectomy }\end{array}$ \\
\hline
\end{tabular}


fertility issues. Of the women who would not prefer transvaginal surgery, a significant number indicated concerns over infectious issues.

\subsection{Current challenges and future perspectives in urological natural orifice transluminal endoscopic surgery and laparoendoscopic single-site surgery}

3.5.1. Which objective data suggest advantages of scarless surgery? Early clinical experience has shown that NOTES urologic surgery using currently available instruments is indeed possible. Nevertheless, because of the immaturity of the instrumentation, early cases have demanded a technical virtuosity that still precludes widespread application of this approach. Clinical experience to date has indicated that LESS surgery can safely and effectively be performed in a variety of urologic settings. As clinical experience increases, expanding indications are expected to be documented and the efficacy of the procedure to improve. Unfortunately, the quality of evidence of all available studies remains low, mostly being small case series [61-63] (evidence level 4) or case-control studies from selected centers [64-71] (evidence level 3b). Given the limited amount of data, available reviews are narrative $[11,13,14,29-31,78,79]$ or are based on expert opinions and consensus meetings $[1,2,80]$ (evidence level 4).

Thus far, the advantages of LESS still exist at a theoretical level, because no clear benefit on postoperative course and patient convalescence has been definitively proven. The only potential benefit of LESS remains the claimed cosmetic outcome. Prospective, randomized studies are largely awaited to determine which LESS procedures will be established and which are unlikely to stand the test of time (Table 9).

Further clinical research, based on sound scientific principles, will define the actual place of LESS in urologists' armamentarium. In the meanwhile, it should be recommended that, together with proper patient selection, a surgeon possess adequate laparoscopic experience and preferably a certain amount of LESS training before embarking on a LESS procedure [80]. This is of utmost importance for minimizing serious complications, such as those seen in early reported series.

\subsubsection{Technology advances in laparoendoscopic single-site surgery and natural orifice transluminal endoscopic surgery: platforms,} robotics, and beyond

The intraoperative ergonomics of instruments for NOTES and LESS represents a major unsolved issue. Technology development is underway and holds promise to minimize the challenging technical nature of scarless surgery.

3.5.2.1. Natural orifice transluminal endoscopic surgery platforms. NOTES is a rapidly developing new technology that depends on collaborative support from engineers, translational clinical researchers, and surgeons. Unfortunately, current endoscopes do not satisfy specific requirements for NOTES applications [81]. Construction of novel instruments specifically designed for NOTES should assist in overcoming many present limitations. Surgical systems and navigation platforms specifically for use in NOTES are being developed and are likely to be available in the near future (Fig. 2).

Table 9 - Laparoendoscopic single-site surgery procedures in urology: estimated difficulty and potential future role

\begin{tabular}{|c|c|c|c|}
\hline Procedure & $\begin{array}{l}\text { Estimated degree } \\
\text { of difficulty }\end{array}$ & Current limitations/concerns & $\begin{array}{l}\text { Potential for } \\
\text { future role in urology }\end{array}$ \\
\hline Cryotherapy $[46,68]$ & Slightly difficult & Lack of specifically designed cryoprobes. & High \\
\hline $\begin{array}{l}\text { Simple nephrectomy } \\
\qquad[11,12,33,35,36,39,40]\end{array}$ & Fairly difficult & $\begin{array}{l}\text { Besides cosmetic advantages, other benefits } \\
\text { for the patient still need to be fully demonstrated. }\end{array}$ & High \\
\hline Radical nephrectomy [40-42] & Fairly difficult & $\begin{array}{l}\text { Oncologic efficacy to be demonstrated. } \\
\text { Large incision to remove the specimen hinders } \\
\text { the advantages of the single-site procedure. }\end{array}$ & Medium \\
\hline Sacral colpopexy $[6,69]$ & Difficult & Demanding suturing. & Medium \\
\hline Pyeloplasty $[39,5,65,85]$ & Difficult & Demanding suturing. & High \\
\hline Ureteral re-implantation [51] & Difficult & Demanding suturing & High \\
\hline Adrenalectomy $[52,67]$ & Difficult & Need for extraumbilical insertion of the multichannel port. & Low \\
\hline Partial nephrectomy $[43,45]$ & Very difficult & $\begin{array}{l}\text { Challenging reconstructive part of the procedure (risk of bleeding). } \\
\text { Risk for prolonged warm ischemia time. }\end{array}$ & Medium \\
\hline Simple prostatectomy [57-59] & Very difficult & $\begin{array}{l}\text { Availability of other, established techniques } \\
\text { (eg, TURP, HoLEP, PVP). } \\
\text { Very high complication rate. }\end{array}$ & Low \\
\hline $\begin{array}{l}\text { Living-donor } \\
\text { nephrectomy [48-50] }\end{array}$ & Extremely difficult & $\begin{array}{l}\text { Risk of prolonged warm ischemia time/ } \\
\text { Risk of complication in a healthy individual. }\end{array}$ & Medium \\
\hline Radical prostatectomy [54-56] & Extremely difficult & $\begin{array}{l}\text { Demanding suturing. } \\
\text { Oncologic efficacy to be demonstrated. }\end{array}$ & Medium \\
\hline Radical cystectomy $[60,61]$ & Extremely difficult & $\begin{array}{l}\text { Demanding suturing. } \\
\text { Large incision to remove the specimen hinders } \\
\text { the advantages of the single-site procedure. } \\
\text { Oncologic efficacy to be demonstrated. }\end{array}$ & Low \\
\hline
\end{tabular}




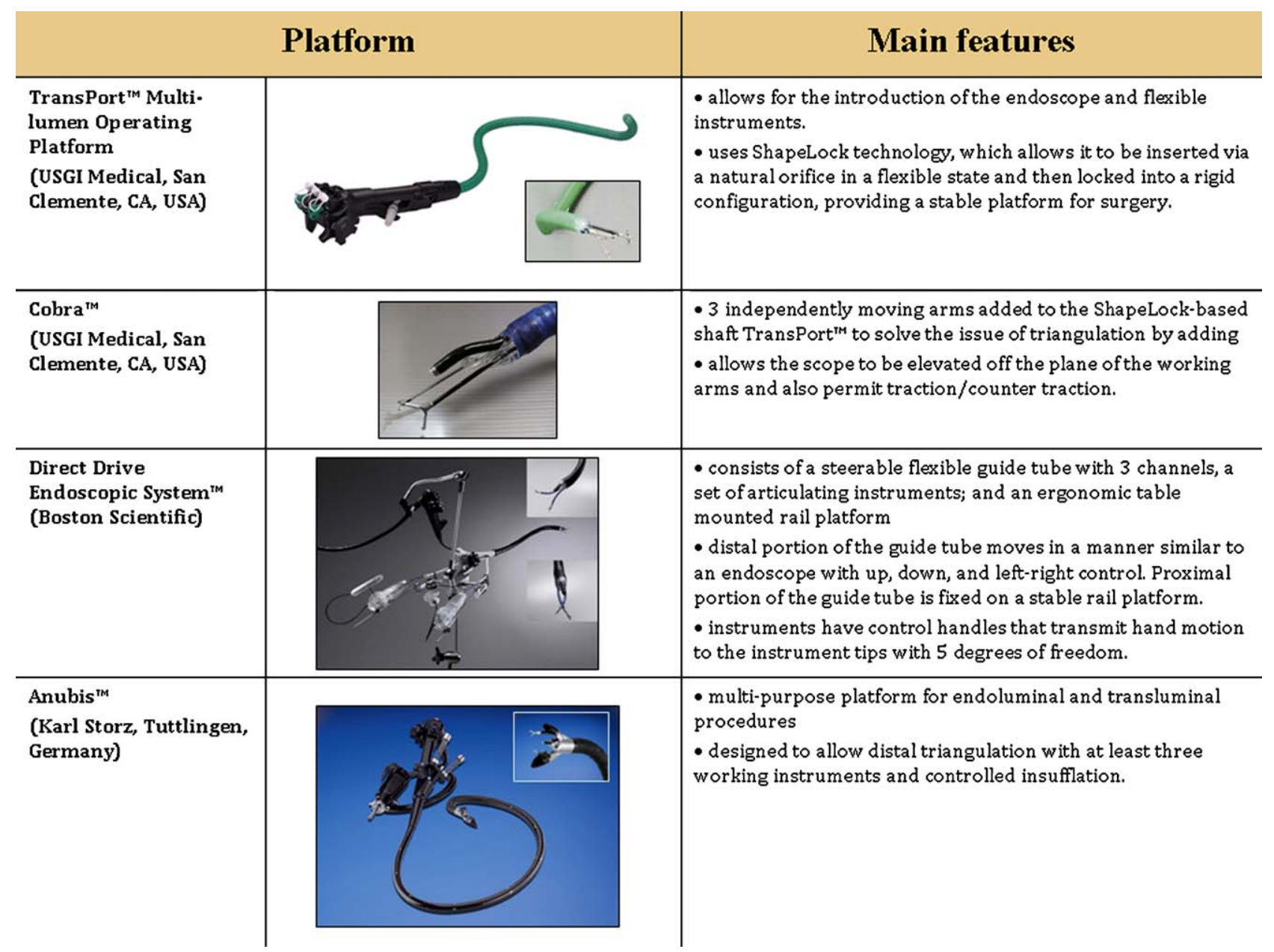

Fig. 2 - Natural orifice transluminal endoscopic surgery platforms.

3.5.2.2. Robotics. The recognized benefits of the da Vinci Surgical System (Intuitive Surgical, Sunnyvale, CA, USA) over conventional laparoscopy include superior ergonomics, optical magnification of the operative field, enhanced surgeon dexterity, and precision of surgical manipulation [82]. Box et al first reported a hybrid NOTES robot-assisted nephrectomy in a porcine model with combined transvaginal and transcolonic access [83]. The authors pointed out that even if currently the robotic system offers many potential advantages, technical difficulties still need to be overcome, including robotic arm collisions, limited triangulation despite the EndoWrist (Intuitive Surgical, Sunnyvale, CA, USA) instruments, and counterintuitive camera angles.

Haber et al adopted a different approach toward robotic NOTES in the porcine model, placing the robotic camera lens and one arm through the umbilicus, with the other robotic arm inserted through the vagina [84]. The authors were able to show the feasibility of robotic NOTES pyeloplasty, PN, and radical nephrectomy, underscoring that incorporating robotics into NOTES will significantly enhance intracorporeal suturing.

Based on their early clinical experience with the STEP technique, Desai et al assessed the technical feasibility of performing transvesical robotic RP in a cadaver model with the aid of the da Vinci S Surgical System [85]. Attempting novel modifications to port and robotic instrument configuration, Kaouk et al reported in 2009 the first successful series of single-port robotic procedures in humans, including RP, dismembered pyeloplasty, and radical nephrectomy [86]. A robotic $12-\mathrm{mm}$ scope and $5-\mathrm{mm}$ grasper were introduced through a single multichannel port, while an additional $5-\mathrm{mm}$ or $8-\mathrm{mm}$ robotic port was introduced through the same umbilical incision $(2 \mathrm{~cm})$ alongside the multichannel port to facilitate entry of robotic instruments. The authors noted less challenging intracorporeal dissecting and suturing using robotic instrument compared to standard LESS. The same group reported an initial experience with single-port robotic PN in two patients without conversions or complications [44]. In another study, they also reported robotic LESS using a GelPort as the access platform [87]. Four clinical procedures were performed, including two pyeloplasties, one radical nephrectomy, and one PN. A $12-\mathrm{mm}$ port for the camera was placed through the GelPort followed by two $8-\mathrm{mm}$ robotic ports and an additional $12-\mathrm{mm}$ port for assistance. All procedures were successfully completed. The use of the GelPort as an access platform provided adequate spacing and flexibility of port placement. Ultimately, the currently 


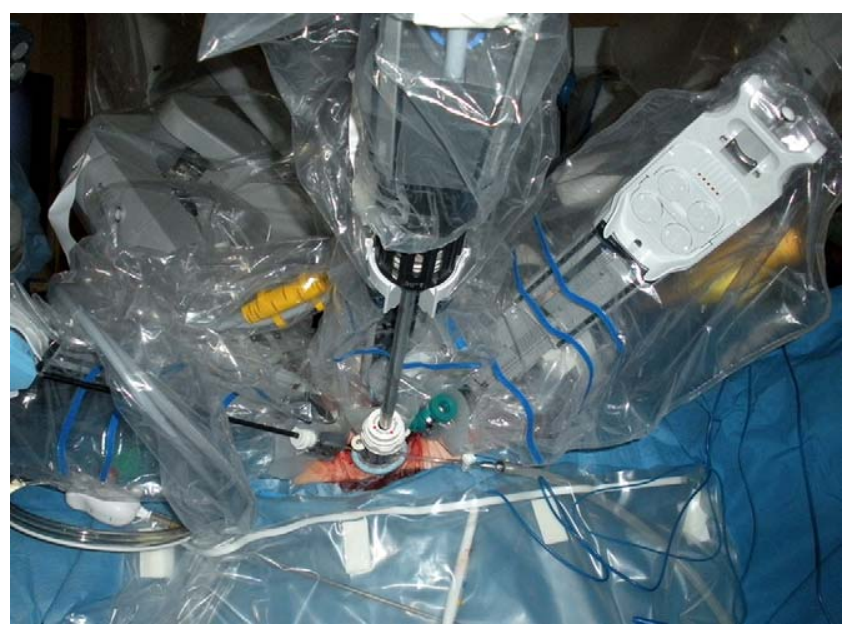

Fig. 3 - Robotic laparoendoscopic single-site surgery: bulky profile of current the da Vinci Surgical System.

available robot remains bulky and not specifically designed for either the NOTES or the LESS technique (Fig. 3).

To address limitations related to the coaxial arrangement of instruments, Joseph et al recently tested in a new technique of "chopstick" surgery enabling the use of current da Vinci robotic arms through a single incision without collision [88]. A preliminary study was conducted in the dry lab in order to determine the optimal setup for LESS-a triangular port arrangement with 2 -cm trocar distance and remote center at the abdominal wall. Then, experiments were conducted utilizing the da Vinci S Surgical System in a porcine model, with three laparoscopic ports introduced through a single incision. Cholecystectomy and nephrectomy were performed utilizing the chopstick technique. This arrangement crosses the instruments at the abdominal wall so that the right instrument is on the left side of the target and the left instrument is on the right, preventing collision of the external robotic arms. To correct for the change in handedness, the robotic console is instructed to drive the "left" instrument with the right hand effector and the "right" instrument with the left. According to the investigators, chopstick surgery significantly enhances the functionality of the surgical robot when working through a single small incision.

In an attempt to minimize clashing of instruments, Crouzet et al recently presented their initial translational animal study, in which a low-profile robot was used to assist one surgeon to complete LESS renal procedures [89]. A single port was placed through a $2-\mathrm{cm}$ umbilical incision, and an operative $5-\mathrm{mm}, 30^{\circ}$ rigid laparoscope was introduced and securely held using a novel low-profile robot under foot and/ or voice control (ViKY System, EndoControl, Grenoble, France).

Even if the addition of the da Vinci Surgical System to LESS has improved limitations experienced with standard LESS, a reduction in the range of motion of the instruments still exists, and we do not have a perfect system and are in the infancy of robotic single-site surgery [90].
3.5.2.3. Magnetic anchoring and guidance system. A magnetic anchoring and guidance system (MAGS) consists of a moveable magnet- or needle-lockable platform that is positioned intra-abdominally and stabilized by an external magnetic element placed on the abdominal skin [91]. The platform is introduced via a single access port and allows unrestricted intra-abdominal movement and spacing of surgical instruments. Recently, Cadeddu et al presented the first clinical report of LESS procedures utilizing a MAGS camera [92].

\subsubsection{Starting a natural orifice transluminal endoscopic surgery/} laparoendoscopic single-site surgery program: patient selection and other issues

It is likely that early in the development of NOTES, only selected centers with high patient volumes would be able to achieve a satisfactory level of skill with NOTES procedures. The NOTES surgeon may be required to have in-depth knowledge of flexible endoscopy, laparoscopy, and different perspectives on abdominal anatomy. Urologic surgeons to some extent have a diverse operative experience from their training and clinical practice, placing them in a favorable position to develop and adopt this new technology [93].

Despite the promising outcomes so far, LESS requires an experienced laparoscopic surgeon to ensure a safe and successful procedure. The steep learning curve of LESS and the period of time required to adapt fully to its difficulties should be considered. Further refinement of instruments to improve intraoperative ergonomics would provide an easier learning curve.

The Laparo-Endoscopic Single-Site Surgery Consortium for Assessment and Research consortium recommended that before a LESS procedure is performed, the surgeon should possess adequate standard laparoscopic experience and preferably should have undergone specific LESS surgical training, including a stepwise, structured program incorporating inanimate training models, hands-on animal training, observation of clinical procedures, and performance of initial LESS procedures in a mentored and proctored setting [80,94].

When starting LESS, patient-selection criteria are expected to be stricter than with conventional laparoscopy. Sensitivity to the potential for complications is critical, and the threshold for conversion to standard laparoscopy, or even open surgery, must be appropriately low. Disease features (ie, locally advanced disease requires more extensive dissection; abnormal anatomy requires extensive suturing) and patients features (ie, body habitus, BMI, comorbidity score, previous surgery or RT, personal preferences for better cosmetic outcome) are to be considered [80].

\subsubsection{Further steps in clinical research}

Several questions must be answered before LESS could gain wide spread acceptance: Does LESS provide any objective, reproducible benefit over conventional or robot-assisted laparoscopy? And which patient population is most likely to benefit from LESS? Further comparative analyses are still needed to answer these questions. Even if there is a universal agreement that improved cosmesis is clinically apparent, standardized measures have not yet been 

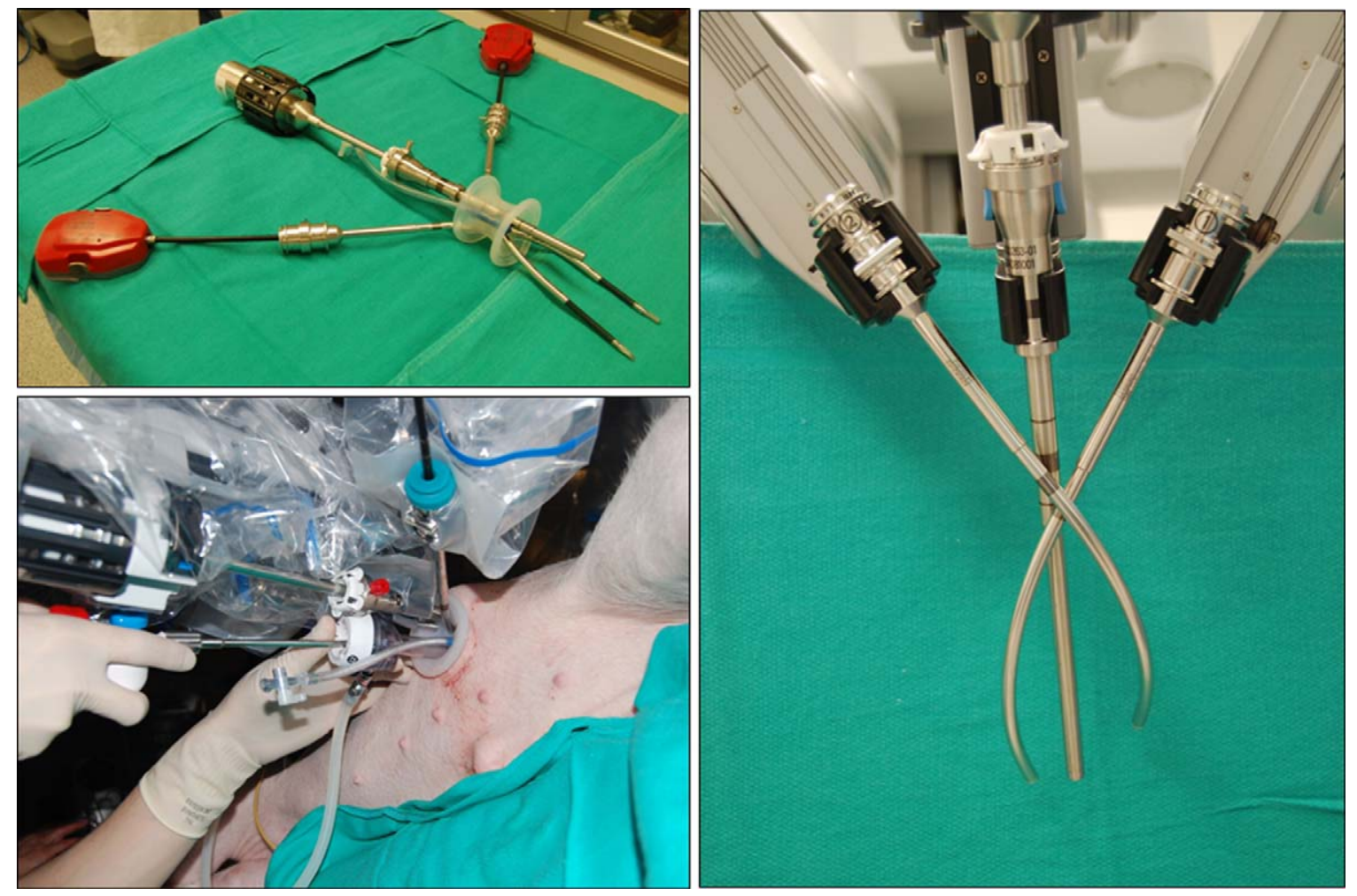

Fig. 4 - A novel robotic instrumentation for laparoendoscopic single-site surgery (VeSPA, Intuitive Surgical, Sunnyvale, CA, USA).

employed to scientifically verify these findings. The true marker for its acceptance will likely be whether LESS shows reduced pain, morbidity, and convalescence, thus justifying the related increase in technical demands and costs.

In this respect, well-designed prospective trials are awaited to compare LESS to conventional laparoscopy, including appropriate QoL and outcome analyses, especially in terms of cosmetic benefit, by using validated patientreported-outcome instruments. Currently available validated tools, such as the SF-12 and SF-36 questionnaires, as well as the standard measures of postoperative morbidity, such as analgesic requirements, may be insufficiently sensitive to detect differences in patient outcomes between LESS and standard laparoscopy. These existing tools may need refinement, or newer tools might need to be developed [80]. Examining the efficacy and safety of new devices on the market and those under development represents a demanding task, and industry is expected to be much more responsive to the needs of urologic surgeons facing this task.

Finally, as the role of robotic surgery is rapidly growing in urology and it is expected that robotics will progressively replace standard laparoscopy, it will be important to see how robotic technology will affect the development of LESS. Robotic instruments dedicated to LESS have recently been introduced and are currently under evaluation [95] (Fig. 4). New robotic systems, including master-slave systems, flexible robots, in vivo miniature robots, or a combination of those systems, might bring NOTES to its full potential in the future [96].

\section{Conclusions}

Even if NOTES claims to be the ultimate frontier of minimally invasive surgery, it currently remains an investigational approach in urology. Refinement of indications and development of instrumentation are expected to define its area of future application. Meticulous work in clinical research and technology development according to sound scientific principles are needed.

LESS has proved to be immediately applicable in the clinical field, being safe and feasible in the hands of experienced laparoscopic surgeons in well-selected patients. Despite promising early outcomes, the benefits of LESS are not obvious at present, with the only claimed advantage being cosmetic.

Prospective randomized studies are largely awaited to define the benefits of this technique for patients as well as to elucidate the cost-effectiveness of the approach. Refinement of instruments and application of robotics are likely to improve intraoperative ergonomics, allowing easier training and facilitating the current steep learning curve.

Author contributions: Riccardo Autorino had full access to all the data in the study and takes responsibility for the integrity of the data and the accuracy of the data analysis.

Study concept and design: Autorino, Montorsi.

Acquisition of data: Autorino.

Analysis and interpretation of data: Autorino, Cadeddu, Desai, Gettman, Gill, Kavoussi, Lima, Richstone, Stolzenburg, Kaouk. 
Drafting of the manuscript: Autorino, Kaouk.

Critical revision of the manuscript for important intellectual content: Cadeddu, Desai, Gettman, Gill, Kavoussi, Lima, Richstone, Stolzenburg, Montorsi, Kaouk.

Statistical analysis: Autorino.

Obtaining funding: None.

Administrative, technical, or material support: None.

Supervision: Montorsi.

Other (specify): None.

Financial disclosures: I certify that all conflicts of interest, including specific financial interests and relationships and affiliations relevant to the subject matter or materials discussed in the manuscript (eg, employment/affiliation, grants or funding, consultancies, honoraria, stock ownership or options, expert testimony, royalties, or patents filed, received, or pending), are the following: None.

Funding/Support and role of the sponsor: None.

\section{References}

[1] Gettman MT, Box G, Averch T, et al. Consensus statement on natural orifice transluminal endoscopic surgery and single-incision laparoscopic surgery: heralding a new era in urology? Eur Urol 2008;53: 1117-20.

[2] Box G, Averch T, Cadeddu J, et al. Nomenclature of natural orifice translumenal endoscopic surgery (NOTES) and laparoendoscopic single-site surgery (LESS) procedures in urology. J Endourol 2008; 22:2575-81.

[3] Breda G, Silvestre P, Giunta A, Xausa D, Tamai A, Gherardi L. Laparoscopic nephrectomy with vaginal delivery of the intact kidney. Eur Urol 1993;24:116-7.

[4] Gill IS, Cherullo EE, Meraney AM, et al. Vaginal extraction of the intact specimen following laparoscopic radical nephrectomy. J Urol 2002;167:238-41.

[5] DeGer S, Peters R, Roigas J, Wille AH, Tuerk IA, Loening SA. Laparoscopic radical cystectomy with continent urinary diversion (rectosigmoid pouch) performed completely intracorporeally: an intermediate functional and oncologic analysis. Urology 2004;64: 935-9.

[6] Gettman MT, Lotan Y, Napper CA, Cadeddu JA. Transvaginal laparoscopic nephrectomy: development and feasibility in the porcine model. Urology 2002;59:446-50.

[7] Kalloo AN, Singh VK, Jagannath SB, et al. Flexible transgastric peritoneoscopy: a novel approach to diagnostic and therapeutic interventions in the peritoneal cavity. Gastrointest Endosc 2004; 60:114-7.

[8] Lima E, Rolanda C, Pego J, et al. Transvesical endoscopic peritoneoscopy: a novel $5 \mathrm{~mm}$ port for intra-abdominal scarless surgery. J Urol 2006;176:802-5.

[9] Kaouk JH, Haber G-P, Goel RK, et al. Pure natural orifice translumenal endoscopic surgery (NOTES) transvaginal nephrectomy. Eur Urol 2010;57:723-6.

[10] Hirano D, Minei S, Yamaguchi K, et al. Retroperitoneoscopic adrenalectomy for adrenal tumors via a single large port. J Endourol 2005;19:788-92.

[11] Tracy CR, Raman JD, Cadeddu JA, Rane A. Laparoendoscopic singlesite surgery in urology: where have we been and where are we heading? Nat Clin Pract Urol 2008;5:561-8.

[12] Raman JD, Bensalah K, Bagrodia A, Stern JM, Cadeddu JA. Laboratory and clinical development of single keyhole umbilical nephrectomy. Urology 2007;70:1039-42.

[13] Autorino R, Stein RJ, Lima E, et al. Current status and future perspectives in laparoendoscopic single-site and natural orifice transluminal endoscopic urological surgery. Int J Urol 2010;17: 410-31.

[14] White WM, Haber GP, Doerr MJ, Gettman M. Natural orifice translumenal endoscopic surgery. Urol Clin North Am 2009;36: 147-155.

[15] Xavier K, Gupta M, Landman J. Transgastric NOTES: current experience and potential implications for urologic applications. J Endourol 2009;23:737-41.

[16] Box GN, Bessler M, Clayman RV. Transvaginal access: current experience and potential implications for urologic applications. J Endourol 2009;23:753-7.

[17] Shin EJ, Kalloo AN. Transcolonic NOTES: current experience and potential implications for urologic applications. J Endourol 2009; 23:743-6.

[18] Granberg CF, Frank I, Gettman MT. Transvesical NOTES: current experience and potential implications for urologic applications. J Endourol 2009;23:747-52.

[19] Lima E, Rolanda C, Correia-Pinto J. NOTES performed using multiple ports of entry: current experience and potential implications for urologic applications. J Endourol 2009;23:759-64.

[20] Lima E, Rolanda C, Osório L, et al. Endoscopic closure of transmural bladder wall perforations. Eur Urol 2009;56:151-8.

[21] Lima E, Rolanda C, Pego JM, et al. Third-generation nephrectomy by natural orifice transluminal endoscopic surgery. J Urol 2007;178: 2648-54.

[22] Clayman RV, Box GN, Abraham JB, et al. Rapid communication: transvaginal single-port NOTES nephrectomy: initial laboratory experience. J Endourol 2007;21:640-4.

[23] Haber GP, Brethauer S, Crouzet S, et al. Pure natural orifice transluminal endoscopic surgery for transvaginal nephrectomy in the porcine model. BJU Int 2009;104:1260-4.

[24] Crouzet S, Haber GP, Kamoi K, et al. Natural orifice translumenal endoscopic surgery (NOTES) renal cryoablation in a porcine model. BJU Int 2008;102:1715-8.

[25] Boylu U, Oommen M, Joshi V, Thomas R, Lee BR. Natural orifice translumenal endoscopic surgery (NOTES) partial nephrectomy in a porcine model. Surg Endosc 2009;24:485-9.

[26] Humphreys MR, Krambeck AE, Andrews PE, Castle EP, Lingeman JE. Natural orifice translumenal endoscopic surgical radical prostatectomy: proof of concept. J Endourol 2009;23:669-75.

[27] Sawyer MD, Cherullo EE, Elmunzer BJ, Schomisch S, Ponsky LE. Pure natural orifice translumenal endoscopic surgery partial cystectomy: intravesical transurethral and extravesical transgastric techniques in a porcine model. Urology 2009;74:1049-53.

[28] Barret E, Sanchez-Salas R, Kasraeian A, et al. A transition to laparoendoscopic single-site surgery (LESS) radical prostatectomy: human cadaver experimental and initial clinical experience. J Endourol 2009;23:135-40.

[29] Boylu U, Oommen M, Thomas R, Lee BR. Transumbilical single-port laparoscopic partial nephrectomy in a pig model. BJU Int 2010; 105:686-90.

[30] Canes D, Desai MM, Aron M, et al. Transumbilical single-port surgery: evolution and current status. Eur Urol 2008;54:102030.

[31] Kommu S, Rane A. Devices for laparoscopic single-site surgery in urology. Expert Rev Med Devices 2009;6:95-103.

[32] Liatsikos E, Kallidonis P, Kyriazis I, et al. Urologic laparoendoscopic single-site surgery. Nat Rev Urol 2009;6:654-9.

[33] Rane A, Rao P, Rao P. Single port access nephrectomy and other laparoscopic urologic procedures using a novel laparoscopic port (R-Port). Urology 2008;72:260-4.

[34] Herati AS, Atalla MA, Rais-Bahrami S, Andonian S, Vira MA, Kavoussi LR. A new valve-less trocar for urologic laparoscopy: initial evaluation. J Endourol 2009;23:1535-9. 
[35] Han WK, Park YH, Jeon HG, et al. The feasibility of laparoendoscopic single-site nephrectomy: initial experience using home-made singleport device. Urology 2010;76:862-5.

[36] Branco AW, Kondo W, Stunitz LC, Filho AJ, de George MA. Transumbilical laparoscopic urological surgery are special devices strictly necessary? BJU Int 2009;104:1136-42.

[37] Raman JD, Cadeddu JA, Rao P, Abbay R. Single-incision laparoscopic surgery: initial urological experience and comparison with naturalorifice transluminal endoscopic surgery. BJU Int 2008;101:1493-6.

[38] Stolzenburg JU, Kallidonis P, Oh MA, et al. Comparative assessment of laparoscopic single-site surgery instruments to conventional laparoscopic in laboratory setting. J Endourol 2010;24:239-45.

[39] Kaouk JH, Haber GP, Goel RK, et al. Single-port laparoscopic surgery in urology: initial experience. Urology 2008;71:3-6.

[40] Rane A, Ahmed S, Kommu SS, Anderson CJ, Rimington PD. Singleport 'scarless' laparoscopic nephrectomies: the United Kingdom experience. BJU Int 104:230-3.

[41] Ponsky LE, Cherullo EE, Sawyer M, et al. Single access site laparoscopic radical nephrectomy: initial clinical experience. J Endourol 2008;22:663-6.

[42] Stolzenburg J-U, Kallidonis P, Hellawell G, et al. Technique of laparoscopic-endoscopic single-site surgery radical nephrectomy. Eur Urol 2009;56:644-50.

[43] Aron M, Canes D, Desai MM, et al. Transumbilical single-port laparoscopic partial nephrectomy. BJU Int 2008;103:516-21.

[44] Rais-Bahrami S, Montag S, Atalla MA, Andonian S, Kavoussi LR, Richstone L. Laparoendoscopic single-site surgery of the kidney with no accessory trocars: an initial experience. J Endourol 2009; 23:1319-24

[45] Kaouk JH, Goel RK. Single-port laparoscopic and robotic partial nephrectomy. Eur Urol 2009;55:1163-70.

[46] Goel RK, Kaouk JH. Single port access renal cryoablation (SPARC): a new approach. Eur Urol 2008;53:1204-9.

[47] Greco F, Hoda MR, Alcaraz A, Bachmann A, Hakenberg OW, Fornara P. Laparoscopic living-donor nephrectomy: analysis of the existing literature. Eur Urol 2010;58:498-509.

[48] Gill IS, Canes D, Aron M, et al. Single port transumbilical (E-NOTES) donor nephrectomy. J Urol 2008;180:637-41.

[49] Ganpule AP, Dhawan DR, Kurien A, et al. Laparoendoscopic singlesite donor nephrectomy: a single-center experience. Urology 2009; 74:1238-40.

[50] Andonian S, Herati AS, Atalla MA, et al. Laparoendoscopic singlesite Pfannenstiel donor nephrectomy. Urology 2010;75:9-12.

[51] Desai MM, Stein R, Rao P, et al. Embryonic natural orifice transumbilical endoscopic surgery (E-NOTES) for advanced reconstruction: initial experience. Urology 2009;73:182-7.

[52] Cindolo L, Gidaro S, Tamburro FR, Schips L. Laparoendoscopic single-site left transperitoneal adrenalectomy. Eur Urol 2010; 57:911-4.

[53] Ryu DS, Park WJ, Oh TH. Retroperitoneal laparoendoscopic single-site surgery in urology: initial experience. J Endourol 2009;23:1857-62.

[54] Kaouk JH, Goel RK, Haber GP, Crouzet S, Desai MM, Gill IS. Singleport laparoscopic radical prostatectomy. Urology 2008;72:1190-3.

[55] White MA, Haber G-P, Autorino R, et al. Robotic laparoendoscopic single-site radical prostatectomy: technique and early outcomes. Eur Urol 2010;58:544-50.

[56] Rabenalt R, Arsov C, Giessing M, Winter C, Albers P. Extraperitoneal laparo-endoscopic single-site radical prostatectomy: first experience. World J Urol. In press. DOI: 10.1007/s00345-010-0534-6.

[57] Desai MM, Aron M, Canes D, et al. Single-port transvesical simple prostatectomy: initial clinical report. Urology 2008;72:960-5.

[58] Sotelo RJ, Astigueta JC, Desai MM, et al. Laparoendoscopic singlesite surgery simple prostatectomy: initial report. Urology 2009;74: 626-630.
[59] Desai MM, Fareed K, Berger AK, et al. Single-port transvesical enucleation of the prostate: a clinical report of 34 cases. BJU Int 2010;105:1296-300.

[60] Kaouk JH, Goel RK, White MA, et al. Laparoendoscopic singlesite radical cystectomy and pelvic lymph node dissection: initial experience and 2-year follow-up. Urology 2010;76:857-61.

[61] White WM, Haber GP, Goel RK, Crouzet S, Stein RJ, Kaouk JH. Singleport urological surgery: single-center experience with the first 100 cases. Urology 2009;74:801-4.

[62] Desai MM, Berger AK, Brandina R, et al. Laparoendoscopic singlesite surgery: initial hundred patients. Urology 2009;74:805-12.

[63] Jeon HG, Jeong W, Oh CK, et al. Initial experience with 50 laparoendoscopic single site surgeries using a homemade, single port device at a single center. J Urol 2010;183:1866-72.

[64] Raman JD, Bagrodia A, Cadeddu JA. Single-incision, umbilical laparoscopic versus conventional laparoscopic nephrectomy: a comparison of perioperative outcomes and short-term measures of convalescence. Eur Urol 2009;55:1198-206.

[65] Tracy CR, Raman JD, Bagrodia A, Cadeddu JA. Perioperative outcomes in patients undergoing conventional laparoscopic versus laparoendoscopic single-site pyeloplasty. Urology 2009;74:102934.

[66] Raybourn 3rd JH, Rane A, Sundaram CP. Laparoendoscopic singlesite surgery for nephrectomy as a feasible alternative to traditional laparoscopy. Urology 2010;75:100-3.

[67] Jeong BC, Park YH, Han DH, Kim HH. Laparoendoscopic single-site and conventional laparoscopic adrenalectomy: a matched casecontrol study. J Endourol 2009;23:1957-60.

[68] White WM, Goel RK, Kaouk JH. Single-port laparoscopic retroperitoneal surgery: initial operative experience and comparative outcome. Urology 2009;73:1279-82.

[69] White WM, Goel RK, Swartz MA, Moore C, Rackley RR, Kaouk JH. Single-port laparoscopic abdominal sacral colpopexy: initial experience and comparative outcomes. Urology 2009;74:1008-12.

[70] Canes D, Berger A, Aron M, et al. Laparo-endoscopic single site (LESS) versus standard laparoscopic left donor nephrectomy: matched-pair comparison. Eur Urol 2010;57:95-101.

[71] Andonian S, Rais-Bahrami S, Atalla MA, Herati AS, Richstone L, Kavoussi LR. Laparoendoscopic single-site Pfannenstiel versus standard laparoscopic donor nephrectomy. J Endourol 2010;24: 429-432.

[72] Branco AW, Branco Filho AJ, Kondo W, et al. Hybrid transvaginal nephrectomy. Eur Urol 2008;53:1290-4.

[73] Alcaraz A, Peri L, Molina A, et al. Feasibility of transvaginal NOTESassisted laparoscopic nephrectomy. Eur Urol 2009;57:233-7.

[74] Sotelo R, de Andrade R, Fernández G, et al. NOTES hybrid transvaginal radical nephrectomy for tumor: stepwise progression toward a first successful clinical case. Eur Urol 2010;57:138-44.

[75] Kaouk JH, White WM, Goel RK, et al. NOTES transvaginal nephrectomy: first human experience. Urology 2009;74:5-8.

[76] Strickland AD, Norwood MG, Behnia-Willison F, Olakkengil SA, Hewett PJ. Transvaginal natural orifice translumenal endoscopic surgery (NOTES): a survey of women's views on a new technique. Surg Endosc 2010;24:2424-31.

[77] Peterson CY, Ramamoorthy S, Andrews B, Horgan S, Talamini M, Chock A. Women's positive perception of transvaginal NOTES surgery. Surg Endosc 2009;23:1770-4.

[78] Eisenberg MS, Cadeddu JA, Desai MM. Laparoendoscopic single-site surgery in urology. Curr Opin Urol 2010;20:141-7.

[79] Irwin BH, Rao PP, Stein RJ, Desai MM. Laparoendoscopic single site surgery in urology. Urol Clin North Am 2009;36:223-35.

[80] Gill IS, Advincula AP, Aron M, et al. Consensus statement of the consortium for laparoendoscopic single-site surgery. Surg Endosc 2010;24:762-8. 
[81] Bardaro SJ, Swanstrom L. Development of advanced endoscopes for natural orifice transluminal endoscopic surgery (NOTES). Minim Invasive Ther Allied Technol 2006;15:378-83.

[82] Rane A, Tan GY, Tewari AK. Laparoendoscopic single-site surgery in urology: is robotics the missing link? BJU Int 2009;104:1041-6.

[83] Box GN, Lee HJ, Santos RJ, et al. Rapid communication: robot-assisted NOTES nephrectomy: initial report. J Endourol 2008;22:503-6.

[84] Haber GP, Crouzet S, Kamoi K, et al. Robotic NOTES (natural orifice translumenal endoscopic surgery) in reconstructive urology: initial laboratory experience. Urology 2008;71:996-1000.

[85] Desai MM, Aron M, Berger A, et al. Transvesical robotic radical prostatectomy. BJU Int 2008;102:1666-9.

[86] Kaouk JH, Goel RK, Haber GP, Crouzet S, Stein RJ. Robotic single-port transumbilical surgery in humans: initial report. BJU Int 2008;103: 366-9.

[87] Stein RJ, White WM, Goel RK, Irwin BH, Haber GP, Kaouk JH. Robotic laparoendoscopic single-site surgery using GelPort as the access platform. Eur Urol 2010;57:132-7.

[88] Joseph RA, Goh AC, Cuevas SP, et al. Chopstick surgery: a novel technique improves surgeon performance and eliminates arm collision in robotic single-incision laparoscopic surgery. Surg Endo 2010; 24:1331-5
[89] Crouzet S, Haber GP, White WM, Kamoi K, Goel RK, Kaouk JH. Single-port, single-operator-light endoscopic robot-assisted laparoscopic urology: pilot study in a pig model. BJU Int 2010;105:682-5.

[90] White MA, Haber GP, Kaouk JH. Robotic single-site surgery. Curr Opin Urol 2010;20:86-91.

[91] Zeltser IS, Bergs R, Fernandez R, et al. Single trocar laparoscopic nephrectomy using magnetic anchoring and guidance system in the porcine model. J Urol 2007;178:288-91.

[92] Cadeddu J, Fernandez R, Desai M, et al. Novel magnetically guided intra-abdominal camera to facilitate laparoendoscopic single-site surgery: initial human experience. Surg Endosc 2009;23:1894-9.

[93] Gamboa AJ, Box GN, Preminger GM, McDougall EM. NOTES: Education and training. J Endourol 2009;23:813-9.

[94] Müller EM, Cavazzola LT, Machado Grossi JV, Mariano MB, Morales C, Brun M. Training for laparoendoscopic single-site surgery (LESS). Int J Surg 2010;8:64-8.

[95] Haber G-P, White MA, Autorino R, et al. Novel robotic da Vinci instruments for laparoendoscopic single-site surgery. Urology. In press. doi: 10.1016/j.urology.2010.06.070.

[96] Canes D, Lehman AC, Farritor SM, Oleynikov D, Desai MM. The future of NOTES instrumentation: flexible robotics and in vivo minirobots. J Endourol 2009;23:787-92. 